\title{
Circularly Polarized Microstrip Yagi Array Antenna with Wide Beamwidth and High Front-to-Back Ratio
}

\author{
Yun Hao, ${ }^{1}$ Haomeng Tong, ${ }^{2}$ and Xihong $\mathrm{Ye}^{1}$ \\ ${ }^{1}$ Electronic Information Engineering Department, Zhonghuan Information College, Tianjin University of Technology, \\ Tianjin 300380, China \\ ${ }^{2}$ School of Information Engineering, Zhejiang University of Technology, Zhejiang 310014, China
}

Correspondence should be addressed to Xihong Ye; shiyexihong@163.com

Received 10 October 2015; Revised 16 January 2016; Accepted 27 January 2016

Academic Editor: Symeon Nikolaou

Copyright (C) 2016 Yun Hao et al. This is an open access article distributed under the Creative Commons Attribution License, which permits unrestricted use, distribution, and reproduction in any medium, provided the original work is properly cited.

\begin{abstract}
A circularly polarized (CP) Microstrip Yagi array antenna (MSYA) is designed in order to achieve high front-to-back ratio $R_{(F / B)}$ and high gain over wide range in the forward radiation space. A Wilkinson power divider owning two output ways with the same magnitude and different phase is used to feed the antenna. Parametric studies are carried out to investigate the effects of some key geometrical sizes on the antenna's performance. A prototype of the antenna is fabricated, and good agreement between the measured results and the numerical simulations is observed. The overlap bandwidth of VSWR $\leq 1.5$ and $\mathrm{AR} \leq 3 \mathrm{~dB}$ is about $11 \%$. The steering angle $(\alpha)$ between the peak gain direction and the broadside can achieve $35^{\circ}, R_{(F / B)}$ reaches $19 \mathrm{~dB}$, and the gain at the front point $\left(G_{0}\right)$ is only $4.3 \mathrm{~dB}$ lower than the maximum gain $\left(G_{m}\right)$. The antenna has a wide beamwidth CP radiation pattern over wide spatial range including $0^{\circ} \leq \theta \leq 90^{\circ}$ in vertical plane and $-35^{\circ} \leq \varphi \leq 55^{\circ}$ in horizontal plane.
\end{abstract}

\section{Introduction}

Microstrip antennas (MSAs) are widely used in many kinds of wireless communication systems due to the advantages such as low profile, low cost, and easy conformability to planar or nonplanar bodies [1]. The maximum radiation of the MSAs is often at the broadside direction. However, the MSAs mounted horizontally are required to have the ability to produce the main beam pointing in the direction of elevation plane of a steering angle above the horizon $[2,3]$.

Huang proposed a CP MSYA configuration including a driven patch, one reflector patch, and two director patches [4-7]. The driven patch was fed by two ports with the same magnitude and different phase to achieve circular polarization, and the reflector patch and director patches steered the peak beam from the broadside direction to the end-fire direction, and $\alpha$ could reach $30^{\circ} \sim 40^{\circ}$. Padhi and Bialkowski used the MSYA structure and fed it by an aperture coupling through PBG structure in $X$ band for WLAN communication [8]. This design could enhance the gain and suppress the cross-polarization of the antenna. Unfortunately, the antenna structures proposed had the disadvantages of small $R_{(F / B)}$ and low $G_{0}$.

Yang et al. presented a pattern reconfigurable Yagi patch antenna. It added two smaller patches symmetrically on both sides of the driven patch, and each of the four parasitic patches had a slot loaded which could be controlled by the switches and resulted in three working modes of the antenna [9]. The steering angle $\alpha$ could achieve $60^{\circ}$, but it also had small value of $R_{(F / B)}$. DeJean and Tentzeris proposed a novel MSYA structure [10]. Two parallel patches with the same size and certain distance took the places of each single director patch in Huang's antenna configuration and, moreover, reduced the reflector patch size. The structure increased $R_{(F / B)}$ to $15 \mathrm{~dB}$. However, $G_{0}$ was also small, and the difference between $G_{0}$ and $G_{m}$ marked as $\Delta G$ was $10 \mathrm{~dB}$. At the same time, the antenna was linearly polarized radiation.

In this paper, we present a MSYA drawn on the experience of Gerald R. DeJean's design but with CP radiation pattern by using two ports with the same magnitude and different phase. Moreover, we propose a new type ground plane to enhance the gain at the front radiation point and ensure a high $R_{(F / B)}$ 


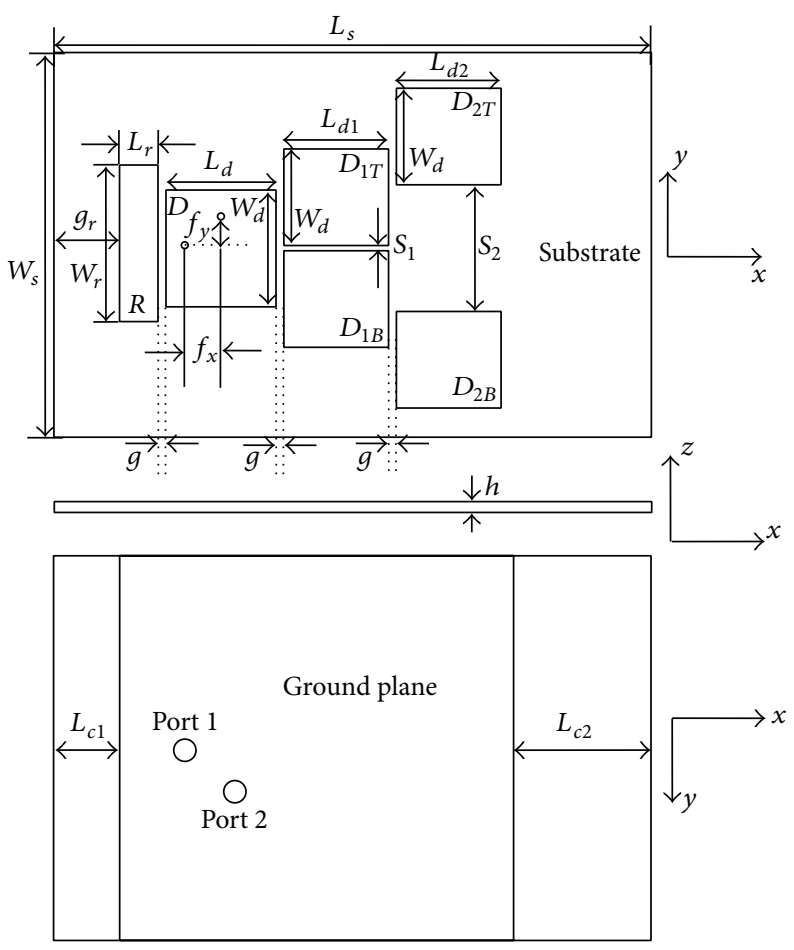

FIgURE 1: The antenna structure.

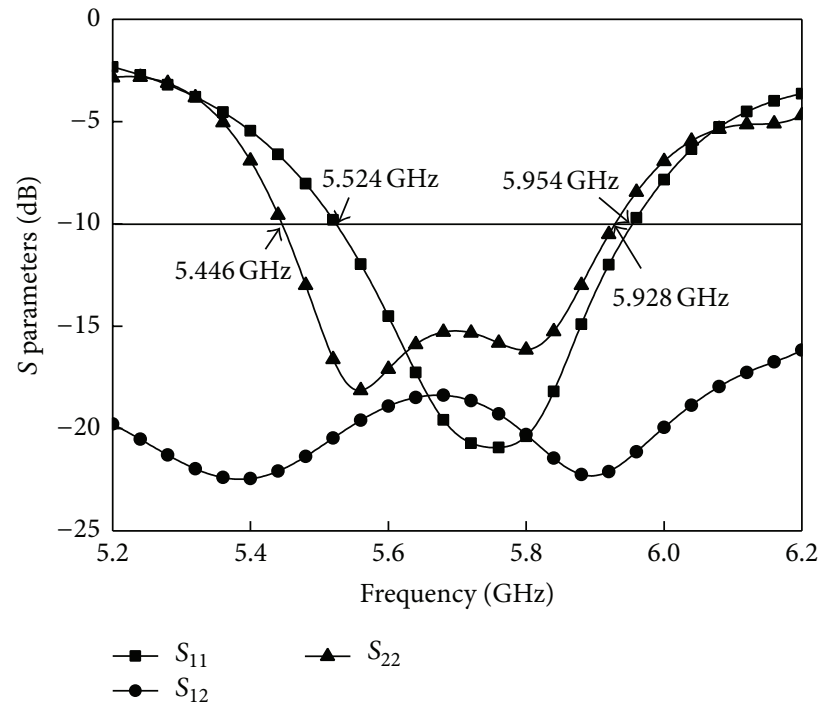

(a) Reflection efficient and isolation

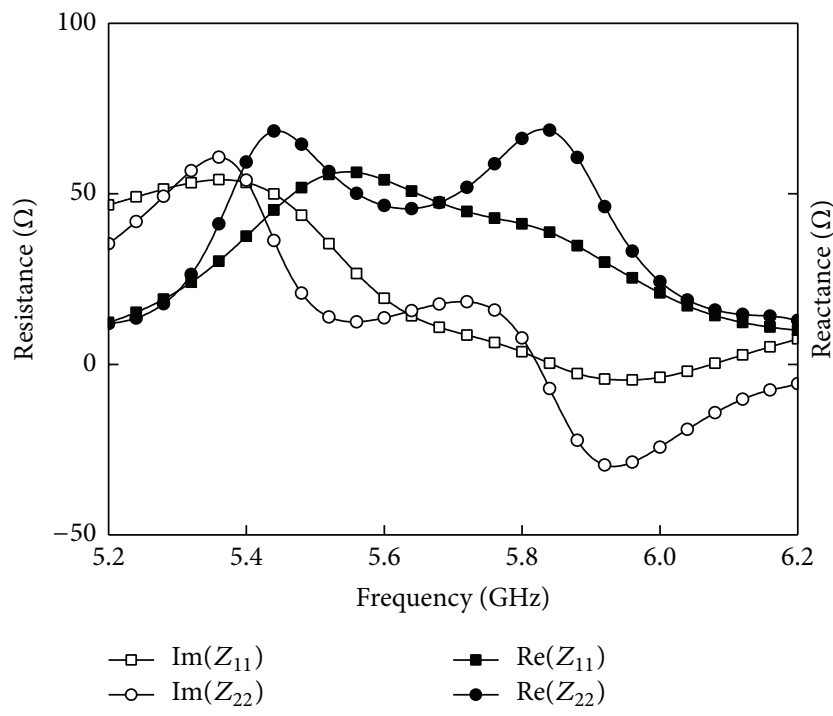

(b) Input impedance

Figure 2: The characteristics of the two ports.

as well as getting a wide CP beamwidth. A Wilkinson power divider owning two output ways with the same magnitude and different phase is used to feed the antenna. The test results show a good agreement with the simulation results.

\section{Antenna Structure}

The antenna structure is shown in Figure 1. $D$ is the driven patch and its dimensions along $x$-axis and $y$-axis are $L_{d}$ and
$W_{d}$, respectively. $R$ is the reflector patch and its dimensions are $L_{r}$ and $W_{r} . D_{1 T}$ and $D_{1 B}$ with the same size form the first stage director, and the distance between them is $S_{1} . D_{2 T}$ and $D_{2 B}$ with the same size form the second stage director, and the distance between them is $S_{2}$. The dimensions of them are $L_{d 1}, W_{d 1}$ and $L_{d 2}, W_{d 2}$, respectively. The gap between each of the adjacent stage patches is $g$. We use two ports which have the same magnitude and different phase to feed the driven patch to achieve CP radiation. The feed positions are along 


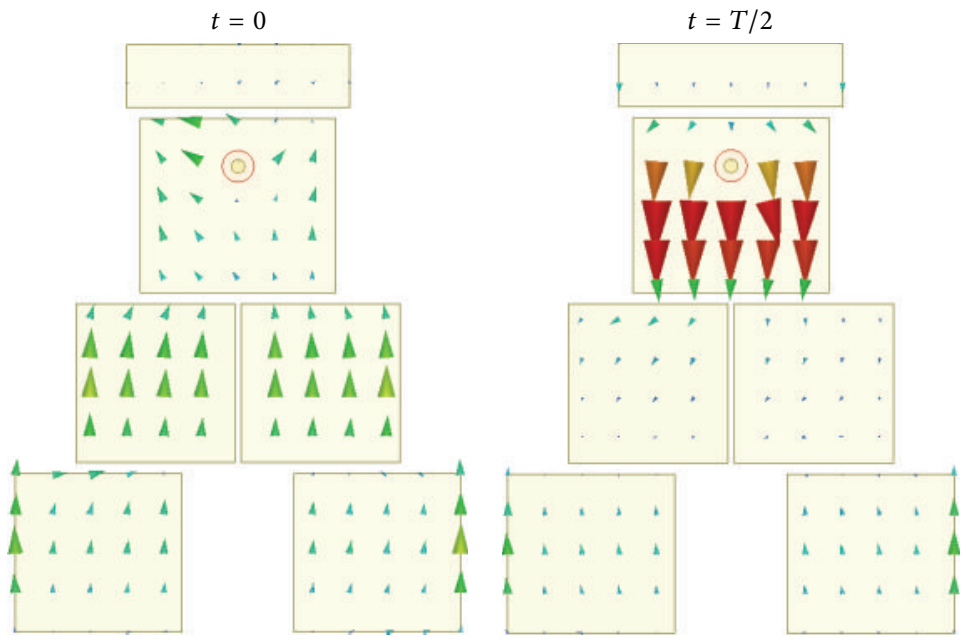

(a) Port 1



(b) Port 2

FIGURE 3: The current distributions on the antenna patches with different port excited.

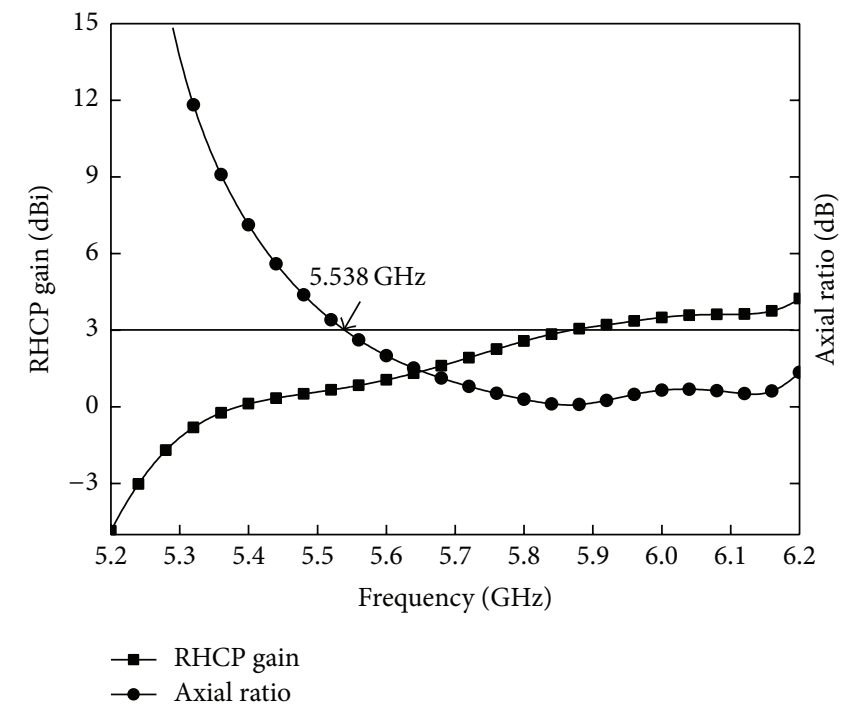

FIgURE 4: The RHCP gain and AR at the front point. 


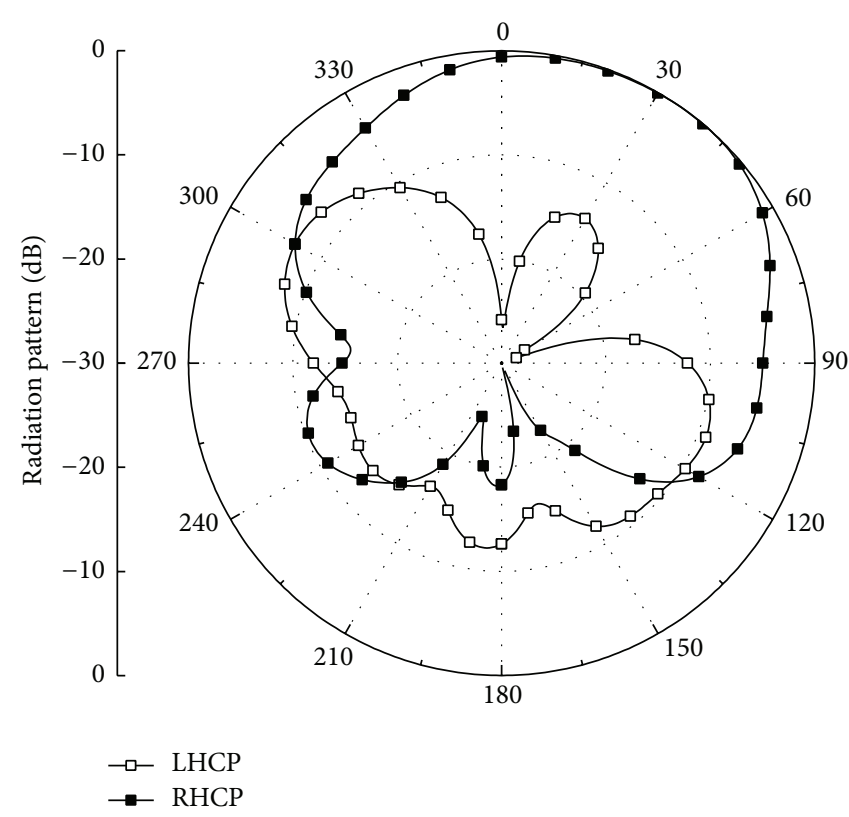

(a) xoy-plane

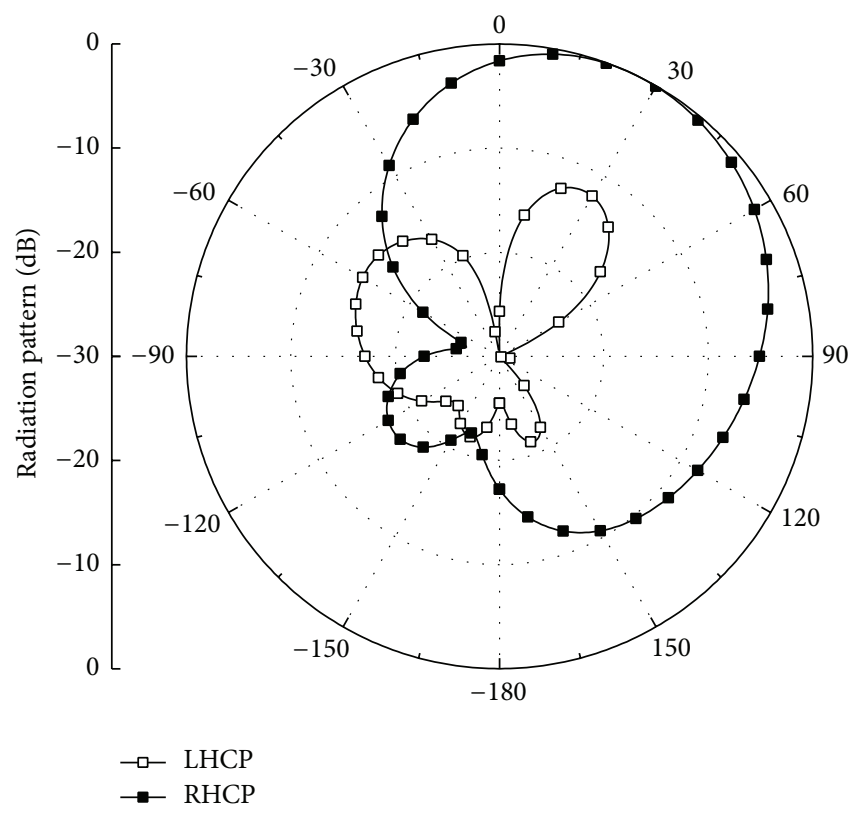

(b) xoz-plane

FIGURE 5: The radiation pattern of the antenna at $5.7 \mathrm{GHz}$.

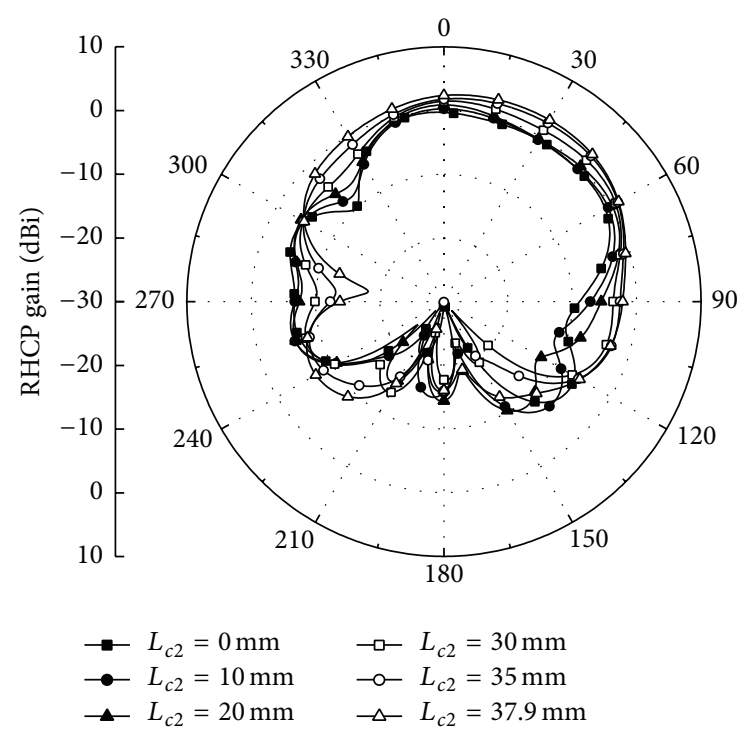

(a) RHCP gain

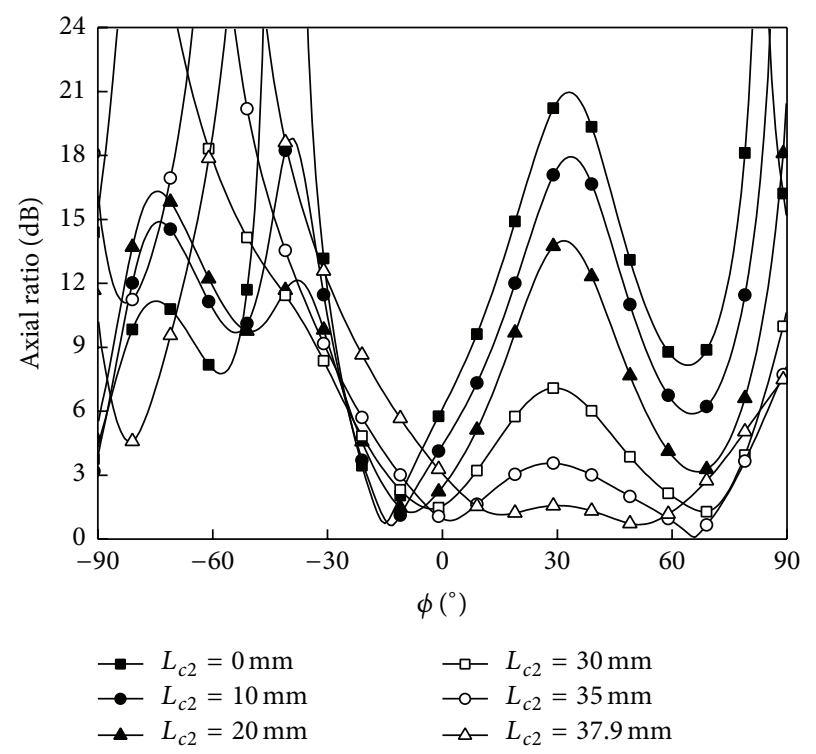

(b) AR

FIgURE 6: The RHCP gain and AR in $x o y$-plane at $5.7 \mathrm{GHz}$ with different $L_{c 2}$.

$x$-axis and $y$-axis and the distances away from the center of the driven patch are $f_{x}$ and $f_{y}$, respectively. The dielectric constant of the substrate is $\varepsilon_{r}$ and the size along $x$-axis and $y$ axis is $L_{s}$ and $W_{s} \cdot g_{r}$ is the distance between the reflector patch and the back end of the substrate. We cut $L_{c 1}$ and $L_{c 2}$ size off the ground plane behind and at the front of the antenna. This ground plane can reduce the reflection wave at the front direction and leak the backward radiation, which makes the radiation power concentrate at the front direction and results in good characteristics of end-fire of the antenna.
The traditional Yagi-Uda dipole array antenna is in free space, and the electromagnetic energy is coupled from the driven element through the space into the reflector and director elements to form end-fire radiation. But the MSYA utilizes the similar principle in MSAs technology, and the electromagnetic energy is coupled from the driven patch to parasitic patches more importantly by the surface wave in the substrate rather than through the space. In conventional Yagi array antenna, as the radiation pattern of a dipole antenna is omnidirectional around its axis, 


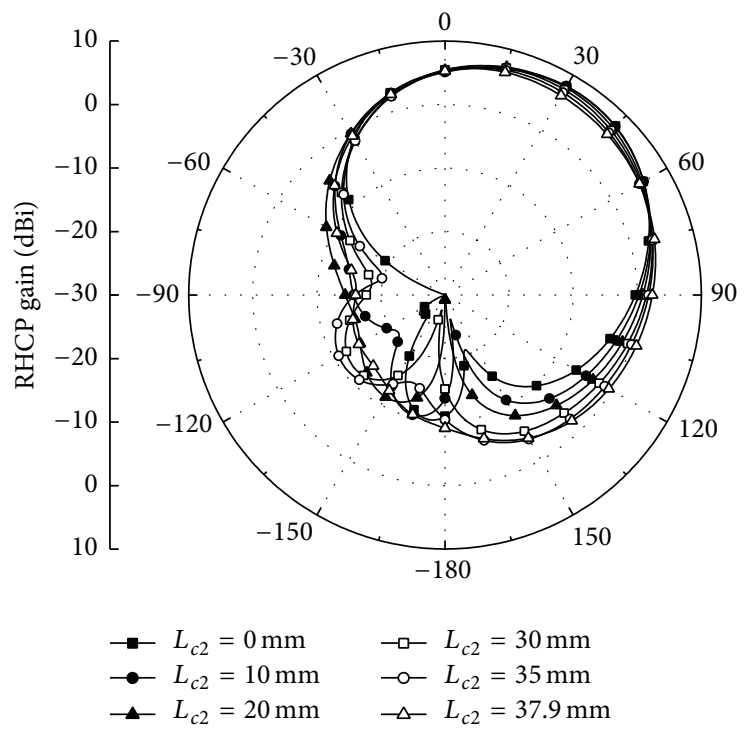

(a) RHCP gain



(b) $\mathrm{AR}$

Figure 7: The RHCP gain and AR in $x o z$-plane at $5.7 \mathrm{GHz}$ with different $L_{c 2}$.

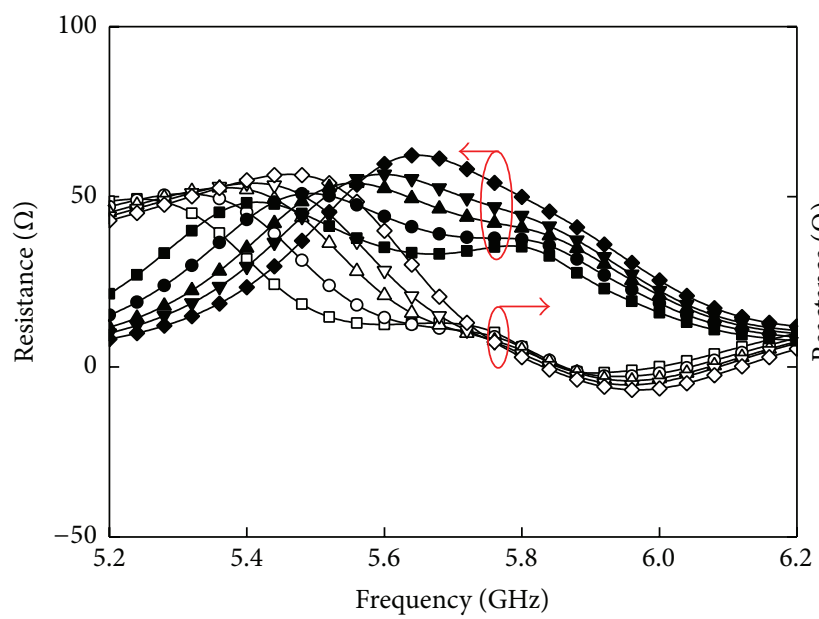

$$
\begin{aligned}
& \text { Resistance } \\
& \because g=0.5 \mathrm{~mm} \\
& \because-g=0.6 \mathrm{~mm} \\
& \multimap g=0.7 \mathrm{~mm} \\
& \neg \mathrm{g}=0.8 \mathrm{~mm} \\
& \multimap-g=0.9 \mathrm{~mm}
\end{aligned}
$$

(a) Port 1

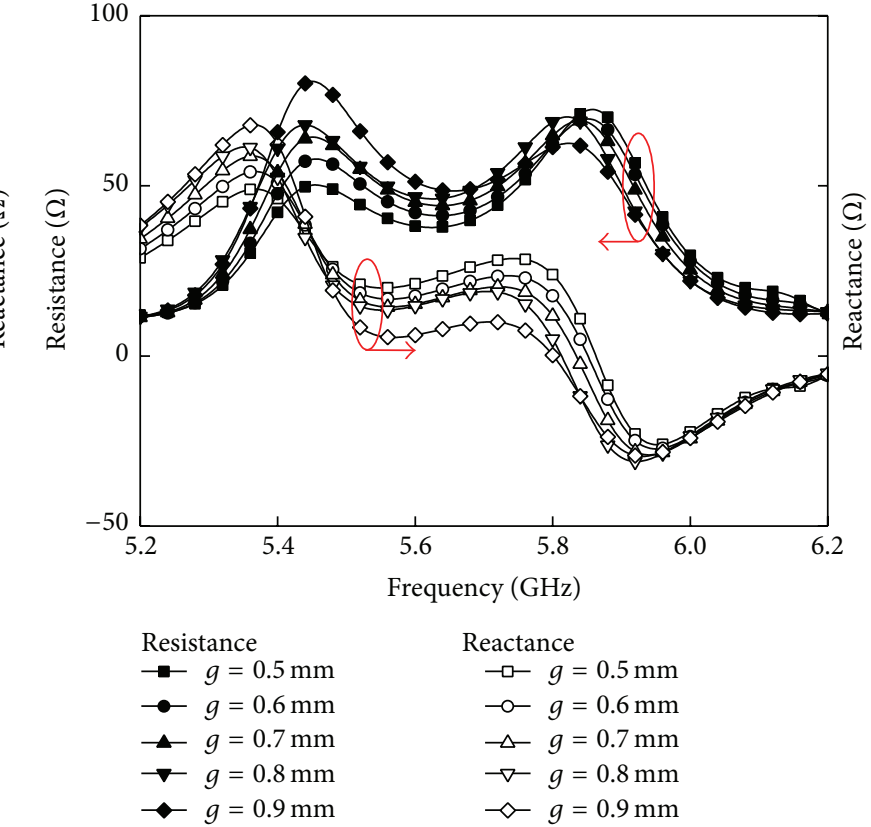

(b) Port 2

FIGURE 8: The impedance of the two ports with different $g$.

the electromagnetic coupling between the driven and the parasitic elements is very strong, and the energy can propagate far away in the front direction. However, because of the broadside radiation characteristic of the MSA element, the energy of the driven element only is transmitted by surface coupling. Furthermore, the surface coupling is weak, so the gap between the element patches in the MSYA should be as close as possible. Moreover, no more than two director patches and one reflector patch are enough because the increasing number of the parasitic patches cannot improve the antenna characteristics obviously, but enlarge the geometric size of the antenna.

\section{Parametric Analysis}

In this part, with the help of ANSYS HFSS solver, the optimal parameters of the antenna working at the central operating frequency (about $5.7 \mathrm{GHz}$ ) are summarized in Table 1. 


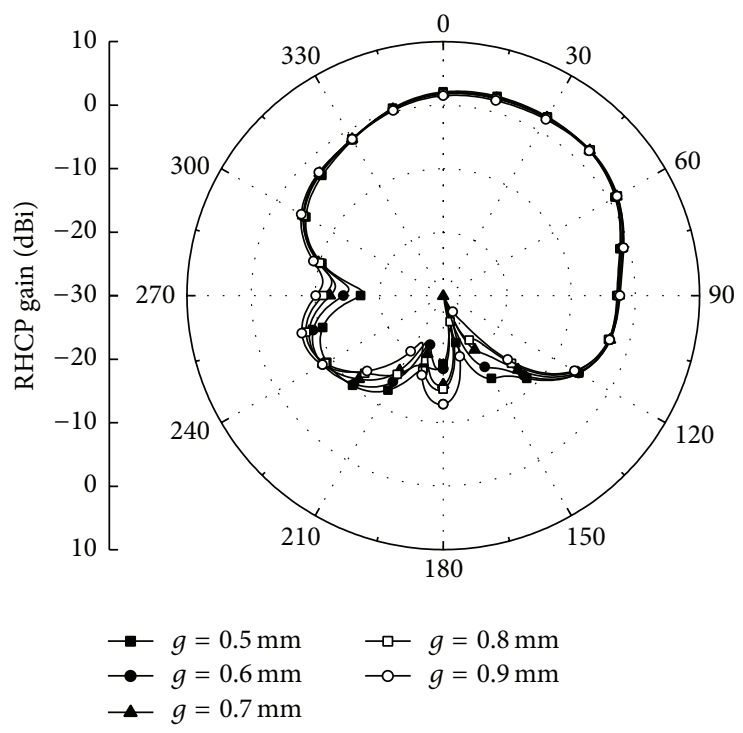

(a) RHCP gain

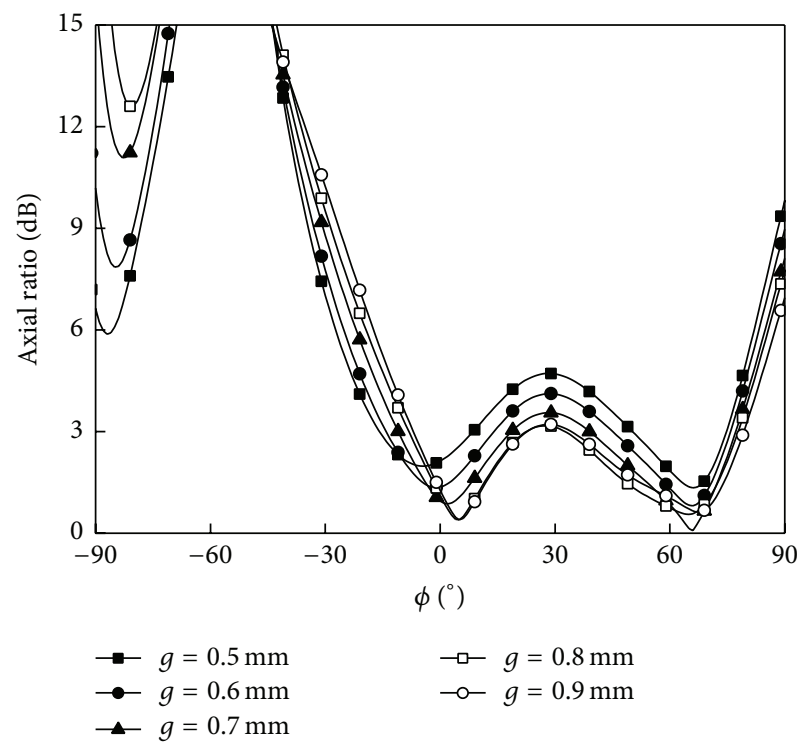

(b) $\mathrm{AR}$

FIgURE 9: The RHCP gain and AR in $x o y$-plane at $5.7 \mathrm{GHz}$ with different $g$.

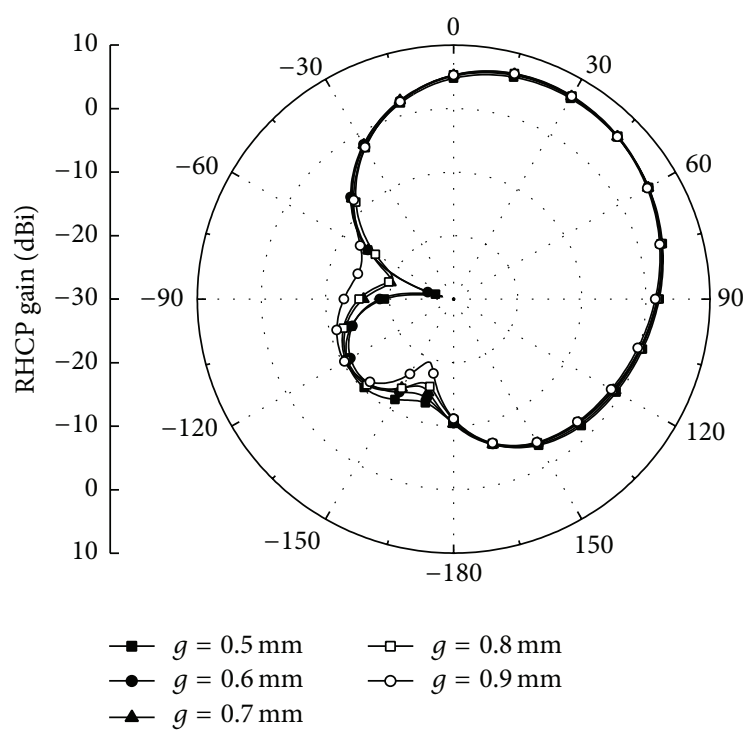

(a) RHCP gain

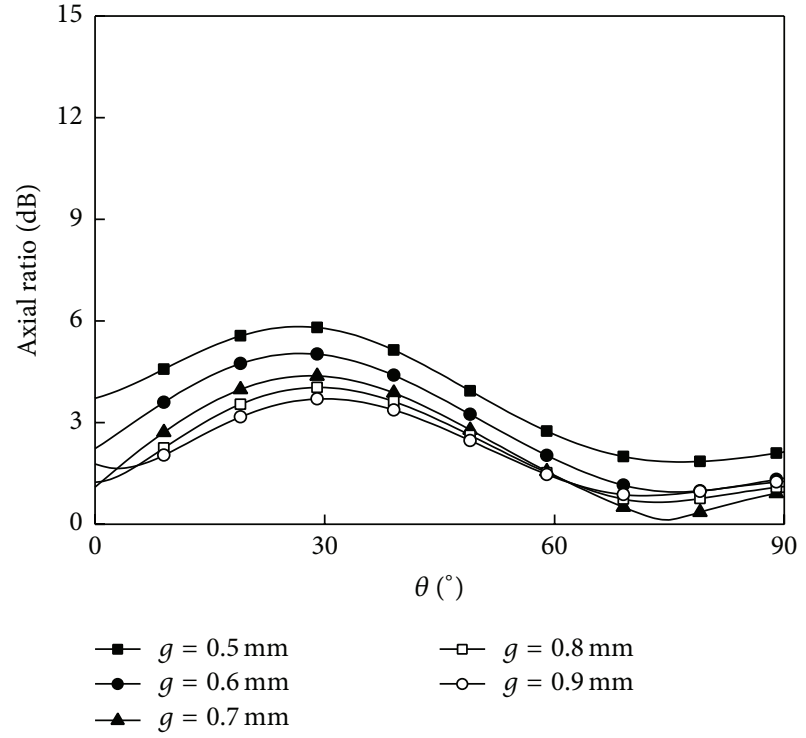

(b) $\mathrm{AR}$

Figure 10: The RHCP gain and AR in $x o z$-plane at $5.7 \mathrm{GHz}$ with different $g$.

The dielectric constant $\varepsilon_{r}$ of the substrate is 4.5 and the loss tangent $\tan \delta$ is 0.002 . The two ports feed the driven patch with the same magnitude and $140^{\circ}$ phase difference to realize good right hand circularly polarized (RHCP) radiation, which is similar to the discussion in Huang's design that a differently designed MSYA will require a different phase value for the optimized CP quality [7]. The simulation results are shown in Figures 1, 2, 3, and 4 and Table 1.

It can be seen from Figure 2 that both ports have two resonant frequencies due to the different sizes of the driven patch and director patches. The driven patch is attributed to the lower resonant frequency and the director patches decide the higher one. The current distributions on the antenna patches are shown in Figure 3, when the two ports excite the driven patch, respectively. We can study that the current distribution excited by port 1 is along the $x$ direction and the field with $E$-plane coupling. The current distribution excited by port 2 is along the $y$ direction and the field with $H$-plane coupling. We can also know that the E-plane coupling is stronger than $\mathrm{H}$-plane coupling in the figure.

The gain and AR at the front radiation point are shown in Figure 4. It indicates that the values of $\mathrm{AR}$ and gain are $1.76 \mathrm{~dB}$ 

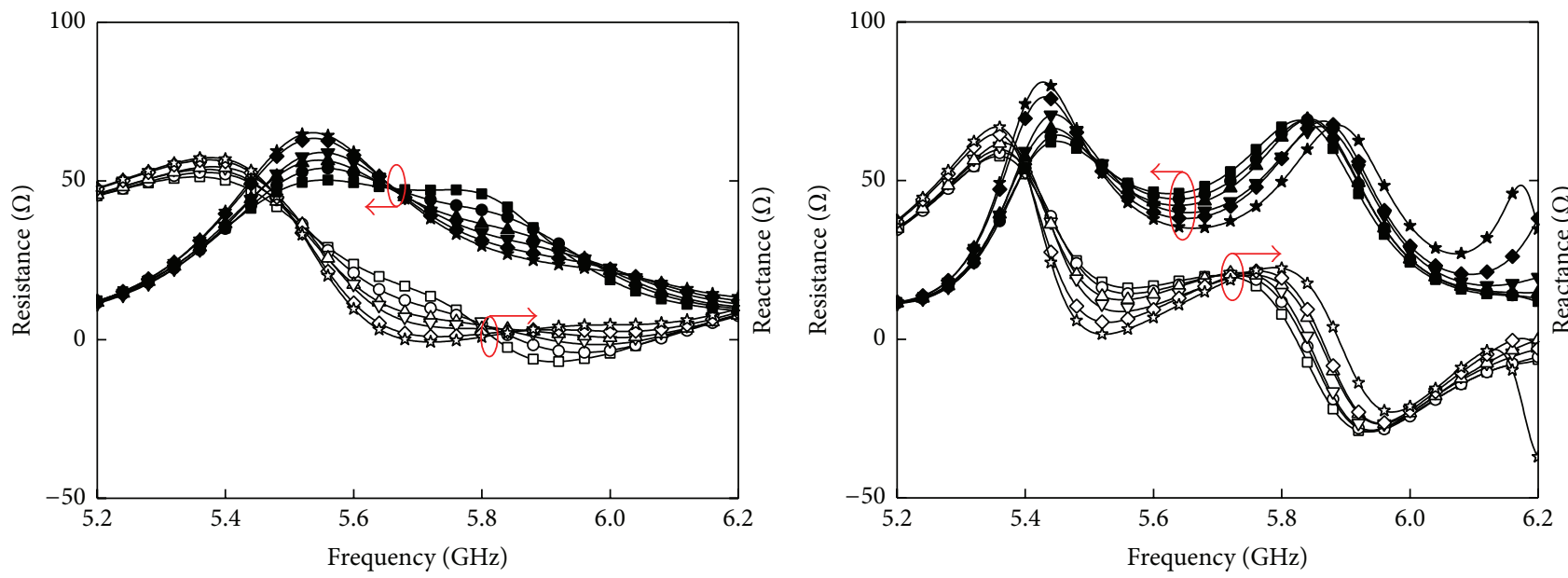

$\begin{array}{ll}\text { Resistance } & \text { Reactance } \\ \rightarrow-S_{2}=5 \mathrm{~mm} & \rightarrow-S_{2}=5 \mathrm{~mm} \\ \rightarrow-S_{2}=7 \mathrm{~mm} & \multimap-S_{2}=7 \mathrm{~mm} \\ \multimap S_{2}=9 \mathrm{~mm} & \rightarrow-S_{2}=9 \mathrm{~mm} \\ \rightarrow S_{2}=11 \mathrm{~mm} & \rightarrow-S_{2}=11 \mathrm{~mm} \\ \multimap-S_{2}=13 \mathrm{~mm} & \multimap-S_{2}=13 \mathrm{~mm} \\ \rightarrow S_{2}=15 \mathrm{~mm} & \rightarrow-S_{2}=15 \mathrm{~mm}\end{array}$

(a) Port 1

$$
\begin{aligned}
& \text { Reactance } \\
& \rightarrow-S_{2}=5 \mathrm{~mm} \\
& \multimap-S_{2}=7 \mathrm{~mm} \\
& \square-S_{2}=9 \mathrm{~mm} \\
& \rightarrow-S_{2}=11 \mathrm{~mm} \\
& \multimap S_{2}=13 \mathrm{~mm} \\
& \multimap-S_{2}=15 \mathrm{~mm}
\end{aligned}
$$

(b) Port 2

FIgURE 11: The impedance of the two ports with different $S_{2}$.

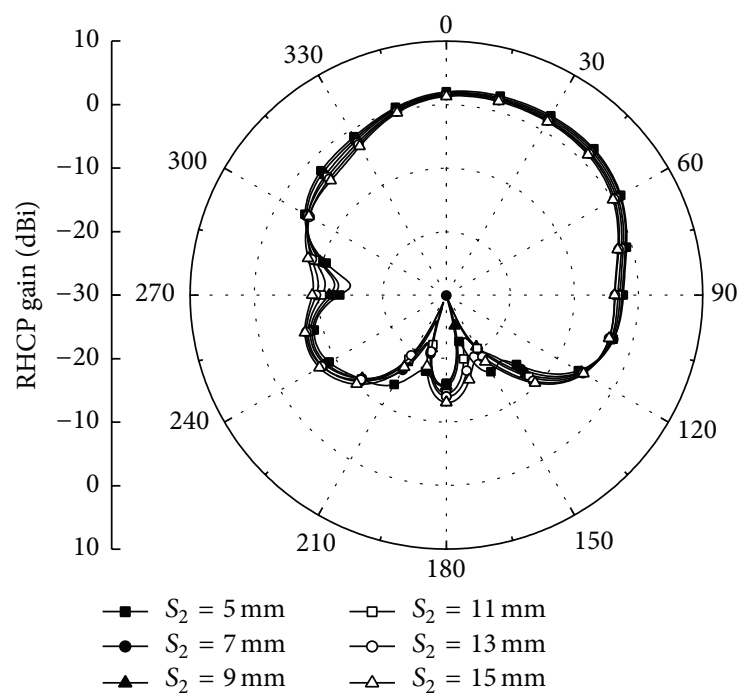

(a) RHCP gain

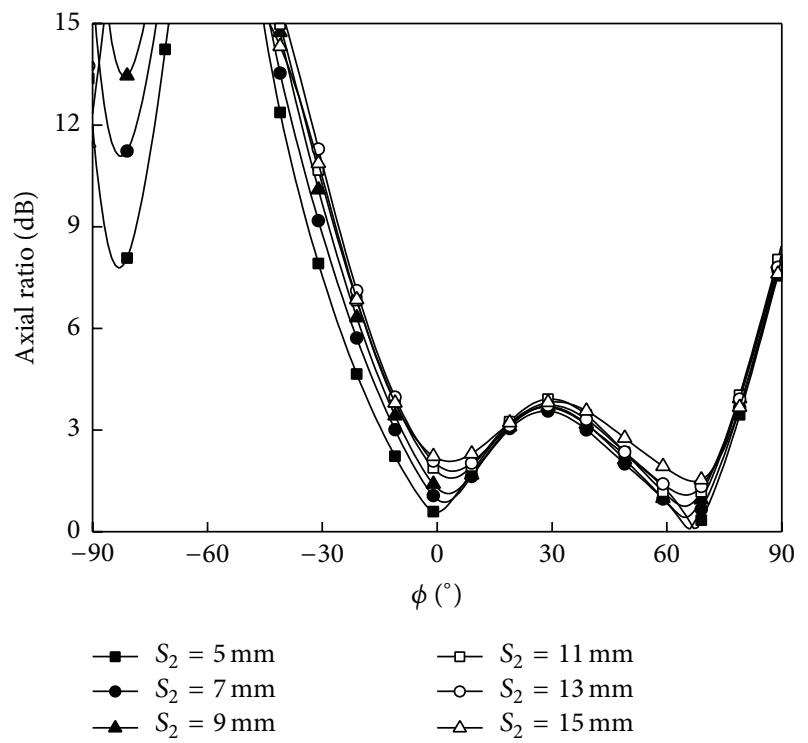

(b) $\mathrm{AR}$

FIgURE 12: The RHCP gain and AR in $x o y$-plane at $5.7 \mathrm{GHz}$ with different $S_{2}$.

TABLE 1: The optimal parameters of the MSYA (unit: $\mathrm{mm}$ ).

\begin{tabular}{cccccccccc}
\hline$L_{s}$ & $W_{s}$ & $h$ & $L_{c 1}$ & $L_{c 2}$ & $g_{r}$ & $g$ & $S_{1}$ & $S_{2}$ \\
\hline 80 & 75 & 1.6 & 5 & 35 & 5 & 0.7 & 0.4 & 7 \\
\hline$W_{r}$ & $L_{r}$ & $W_{d}$ & $L_{d}$ & $W_{d 1}$ & $L_{d 1}$ & $W_{d 2}$ & $L_{d 2}$ & $f_{x}$ \\
\hline 14 & 4 & 12.3 & 11 & 10 & 10 & 10.5 & 10 & 2.5 & 3.3 \\
\hline
\end{tabular}



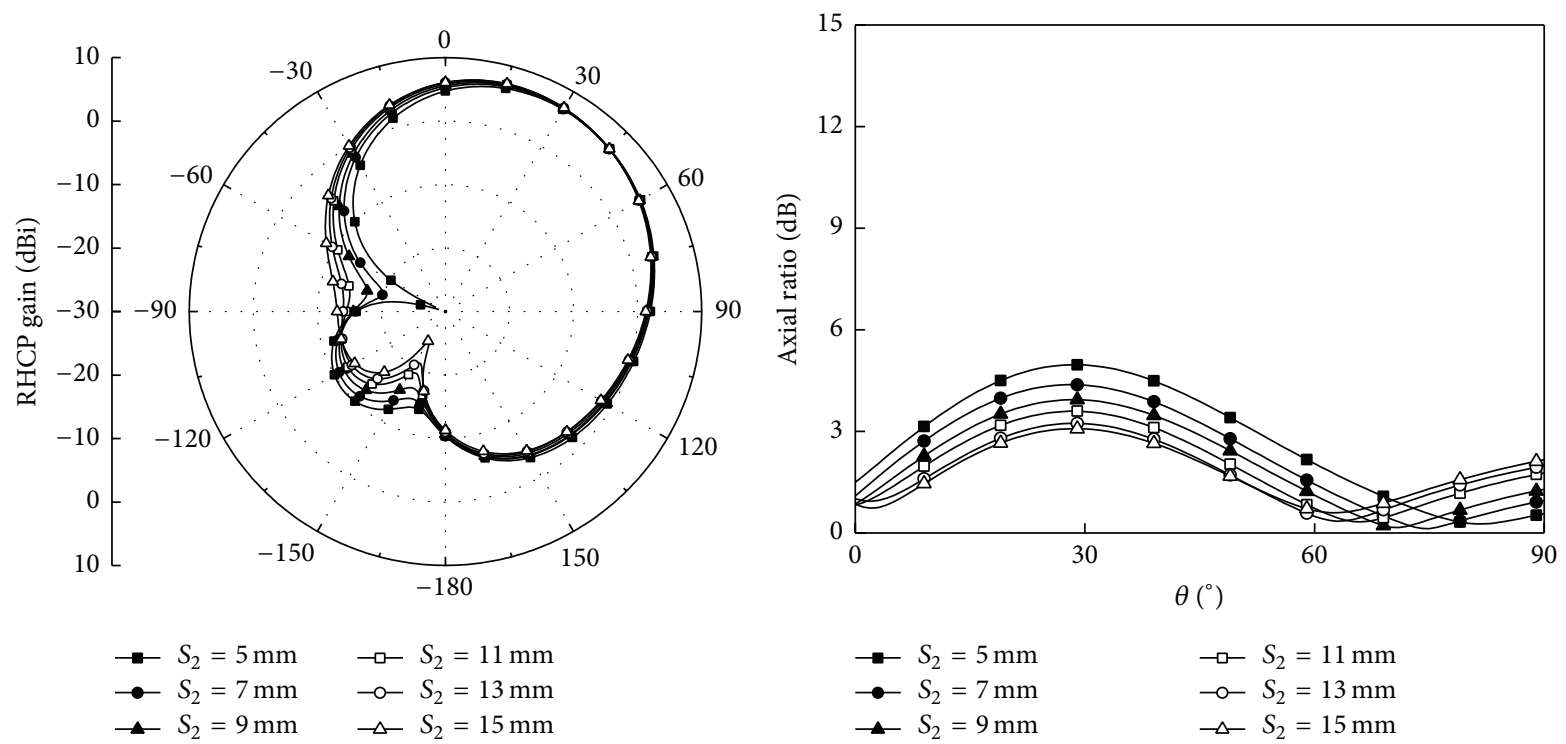

(a) RHCP gain

(b) $\mathrm{AR}$

Figure 13: The RHCP gain and AR in $x o z$-plane at $5.7 \mathrm{GHz}$ with different $S_{2}$.
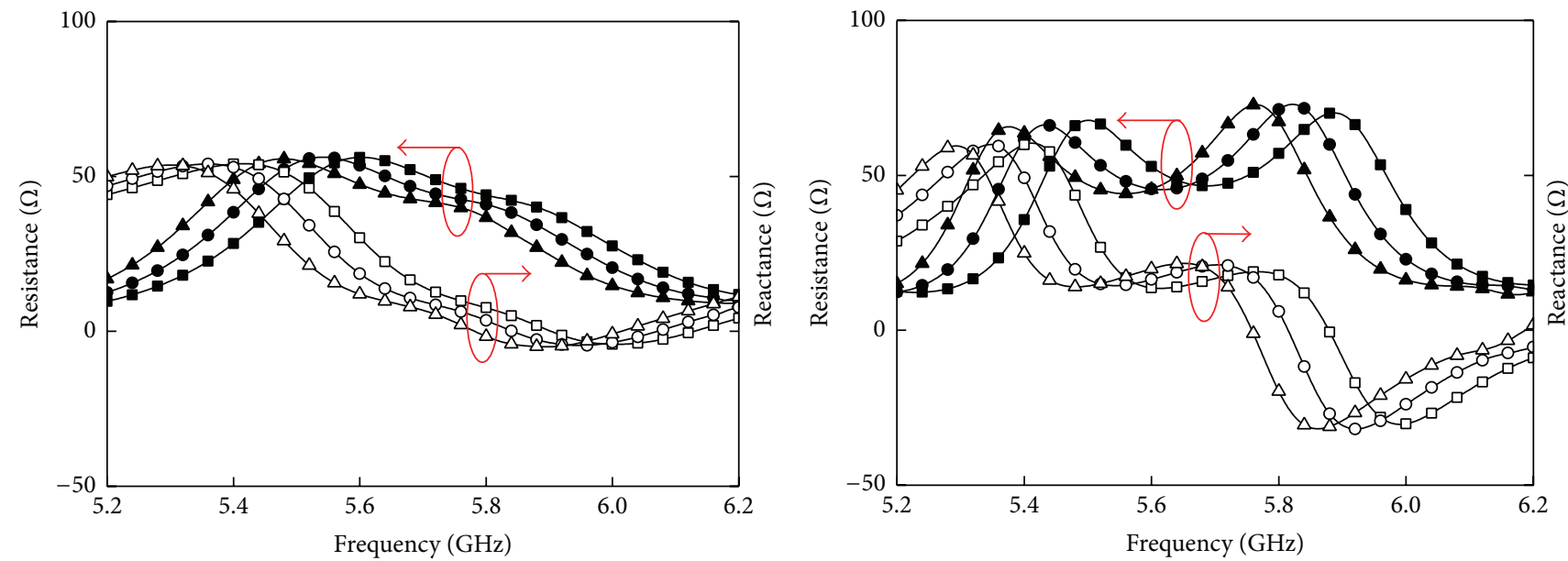

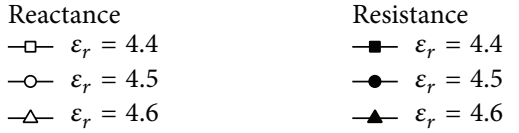

(a) Port 1

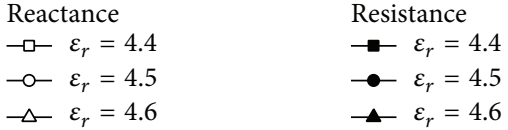

(b) Port 2

FIGURE 14: The impedance of the two ports with different $\varepsilon_{r}$.

TABLE 2: The parameters of the fabricated antenna (unit: $\mathrm{mm}$ ).

\begin{tabular}{|c|c|c|c|c|c|c|c|c|c|}
\hline$L_{s}$ & $W_{s}$ & $h$ & $L_{c 1}$ & $L_{c 2}$ & $g_{r}$ & $g$ & $S_{1}$ & $S_{2}$ & \\
\hline 80 & 75 & 1.5 & 5.2 & 33.5 & 5.2 & 0.72 & 0.62 & 7.2 & \\
\hline$W_{r}$ & $L_{r}$ & $W_{d}$ & $L_{d}$ & $W_{d 1}$ & $L_{d 1}$ & $W_{d 2}$ & $L_{d 2}$ & $f_{x}$ & $\overline{f_{y}}$ \\
\hline 14.4 & 4.10 & 12.70 & 11.4 & 10.3 & 10.3 & 10.3 & 10.3 & 2.6 & 3.8 \\
\hline
\end{tabular}




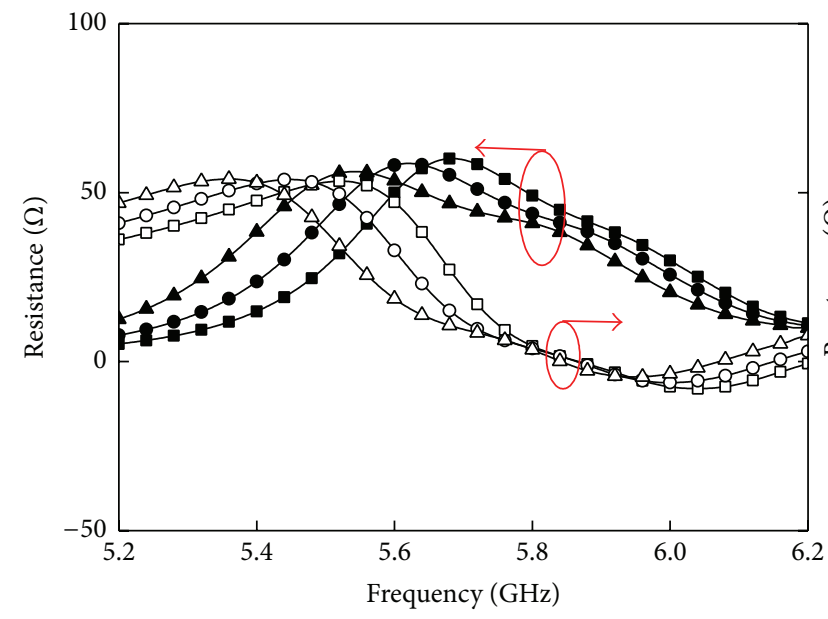

$$
\begin{aligned}
& \text { Reactance } \\
& \square-h=1.4 \mathrm{~mm} \\
& \multimap-h=1.5 \mathrm{~mm} \\
& \square-h=1.6 \mathrm{~mm}
\end{aligned}
$$

(a) Port 1
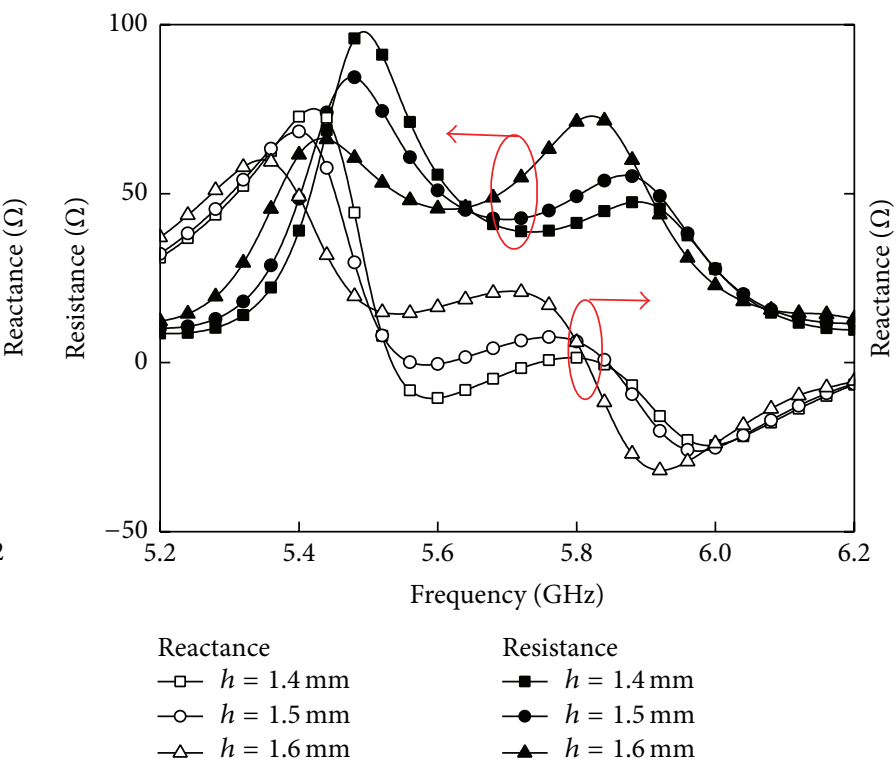

(b) Port 2

FIGURE 15: The impedance of the two ports with different $h$.

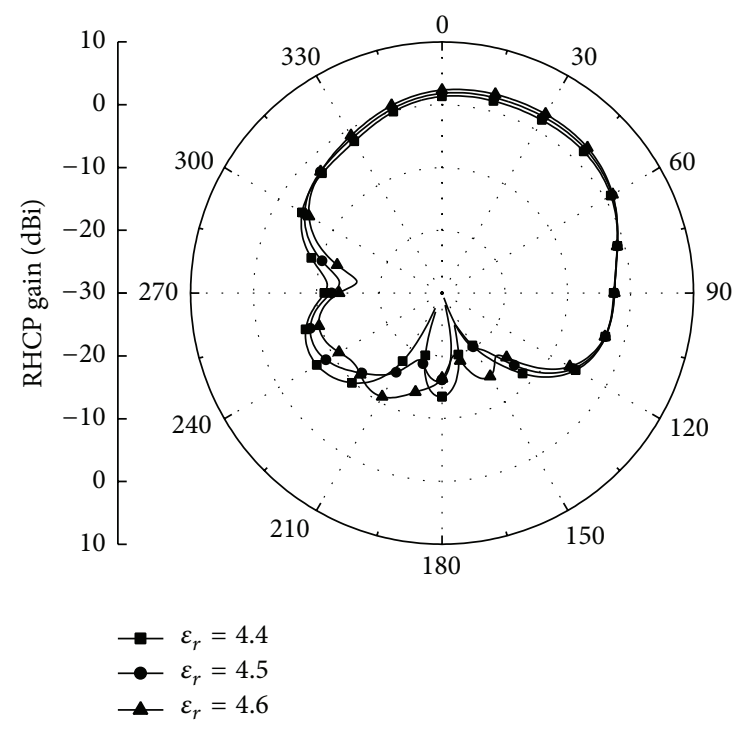

(a) RHCP gain

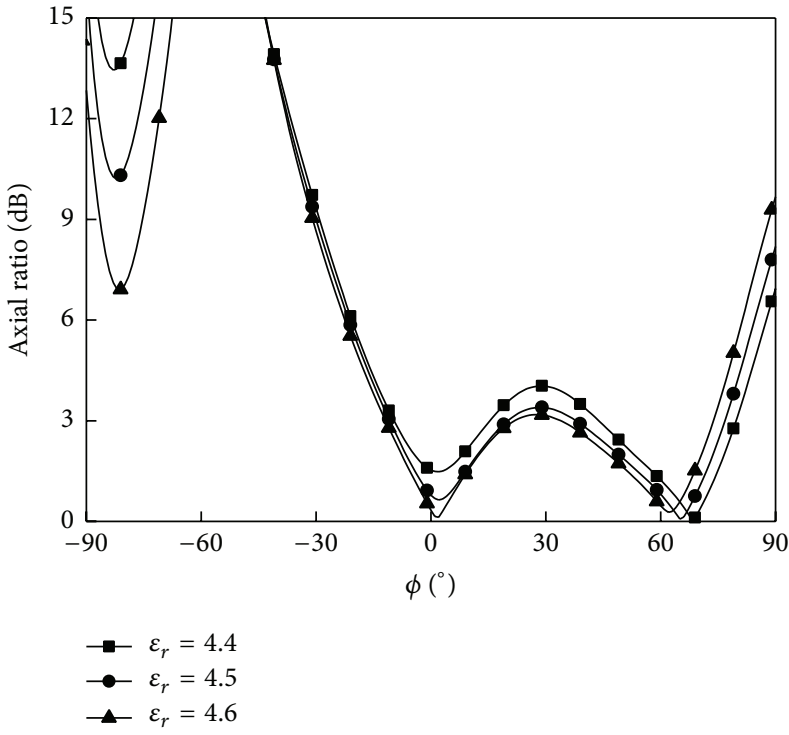

(b) AR

FIGURE 16: The RHCP gain and AR in $x o y$-plane at $5.7 \mathrm{GHz}$ with different $\varepsilon_{r}$.

and $1 \mathrm{dBi}$ at $5.7 \mathrm{GHz}$. The $3 \mathrm{~dB}$ AR bandwidth is $5.54 \mathrm{GHz}$ $\leq f \leq 6.20 \mathrm{GHz}$. Figure 5 shows the radiation patterns of the antenna at $5.7 \mathrm{GHz}$. We can see that the half power beamwidth (HPBW) in horizontal plane (xoy-plane) is $94^{\circ}$ which is wider than the values in other designs mentioned before. At the same time, $\Delta G$ is only $5 \mathrm{~dB}$. Moreover, there is a good CP performance in wide space range.

The effects of some key geometrical sizes on the antenna's performance are investigated in order to provide useful guidelines in design. Note that, in each parametric study, only one parameter varies and the others remain unchanged in Table 1.

3.1. The Size of the Ground Plane $\left(L_{c 2}\right)$. When the value of $L_{c 2}$ is adjusted from $0 \mathrm{~mm}$ to $37.9 \mathrm{~mm}$, the impedance matching of the two ports is slightly varied but the radiation characteristics were significantly changed and the results are shown in Figures 6 and 7. It is found that when a larger part is cut off the ground plane, $G_{0}$ is increased and the CP radiation characteristics become well. But we can also find that when 




(a) RHCP gain

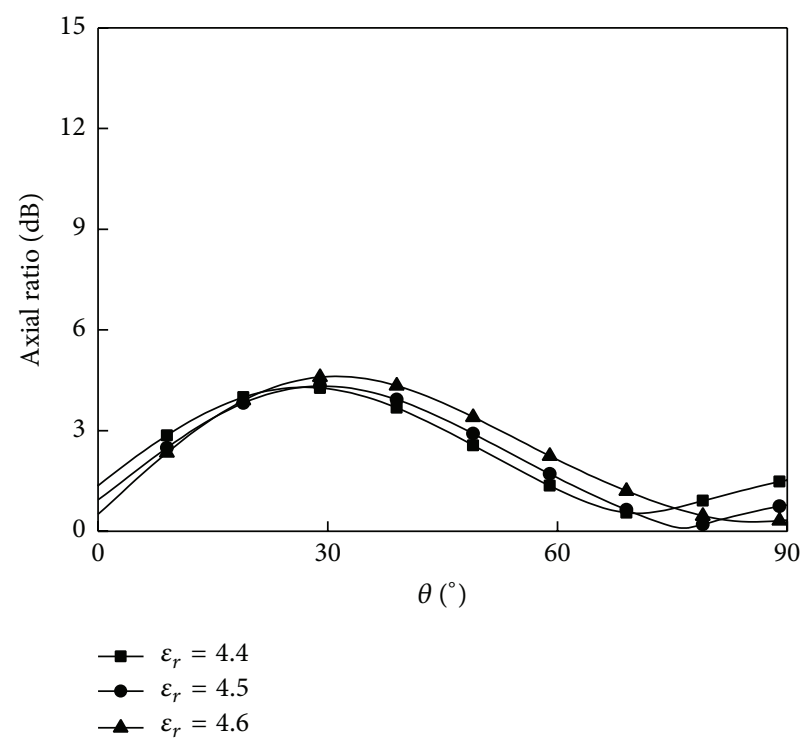

(b) AR

FIgURE 17: The RHCP gain and AR in $x o z$-plane at $5.7 \mathrm{GHz}$ with different $\varepsilon_{r}$.

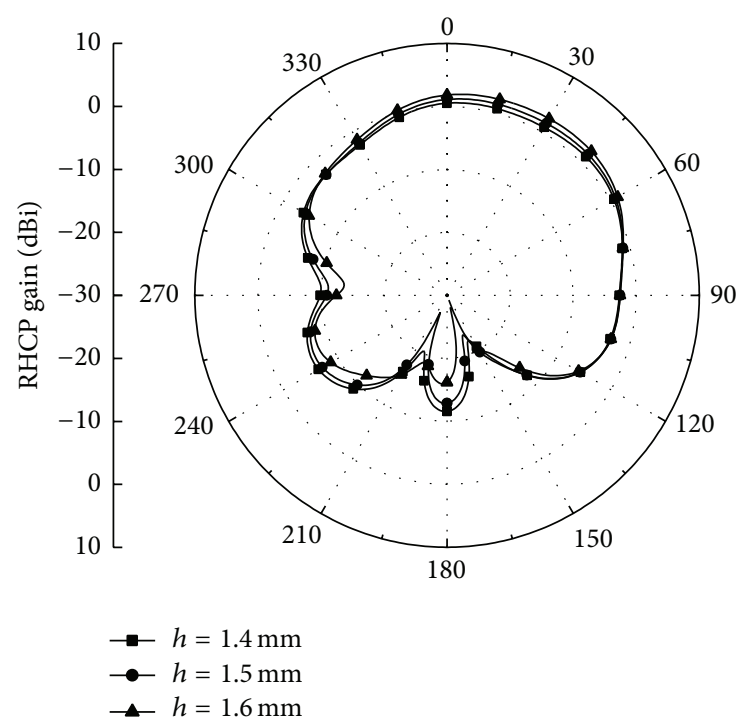

(a) RHCP gain

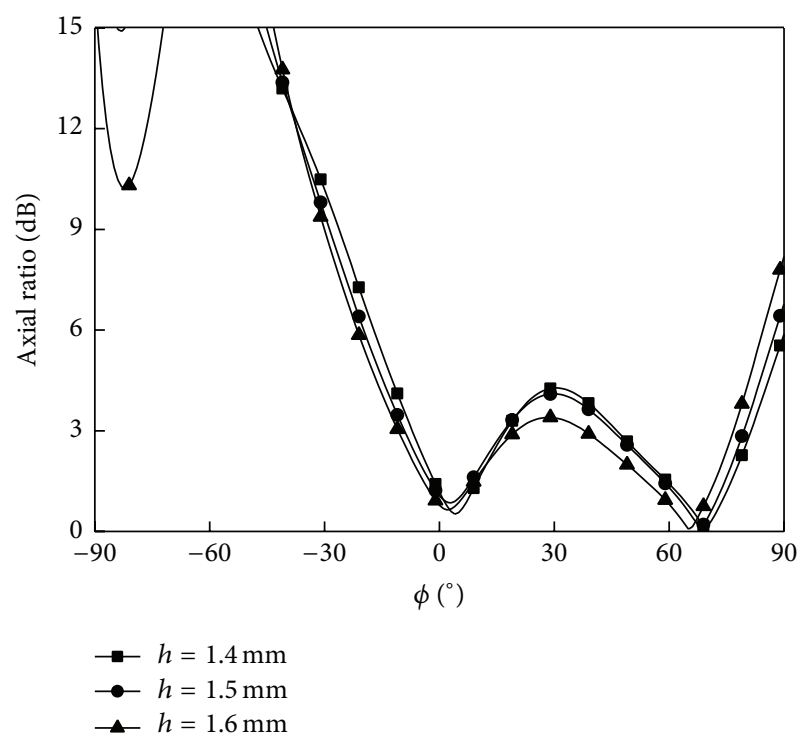

(b) $\mathrm{AR}$

Figure 18: The RHCP gain and AR in $x o y$-plane at $5.7 \mathrm{GHz}$ with different $h$.

$L_{c 2}=37.9 \mathrm{~mm}, \mathrm{AR}$ at front radiation point is worse again and the beamwidth in horizontal plane is narrower.

3.2. The Gap between Two Adjacent Patches $(g)$. We let $L_{s}$ change together with $g$ in order to fix the relative position of the patches and ground when we investigate the effects of the gap $g$ between two adjacent patches on antenna characteristics. Figure 8 shows the impedances of the two ports with different $g$. We find that when $g$ increased, the resonant frequencies of port 1 move to higher band, and the lower resonant frequency is changed more obviously, and the impedance becomes larger. On the other side, the resonant frequencies of port 2 are not significantly changed but the impedance value is varied. The reason is that the current is excited by port 1 along $x$ direction and with $E$-plane coupling. When $g$ is increased, the gap capacitance decreases which makes a weaker coupling between the patches. So the higher resonant frequency corresponding to the director patches becomes weaker. As a result, the two resonant frequencies have gradually evolved into a single resonance from the driven patch. The current excited by port 2 along $y$ direction 


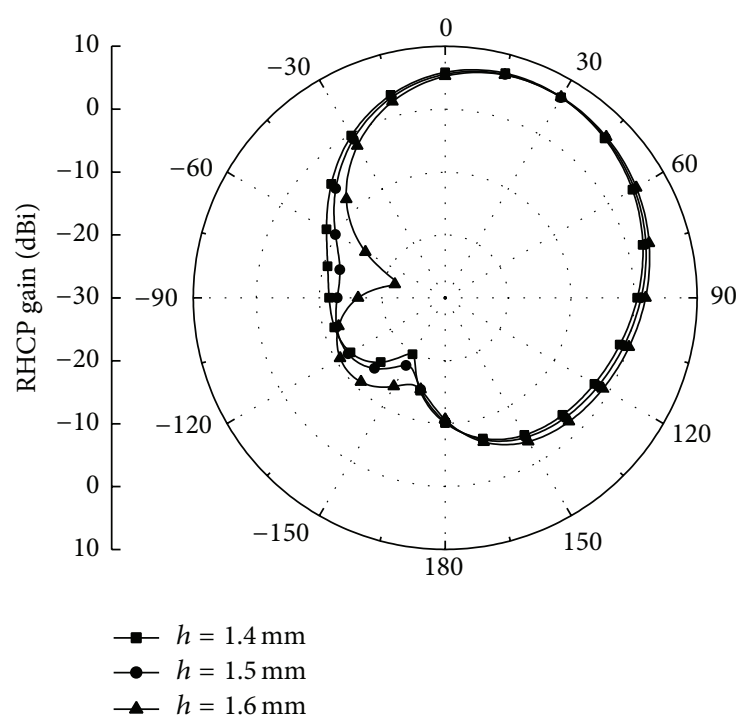

(a) RHCP gain

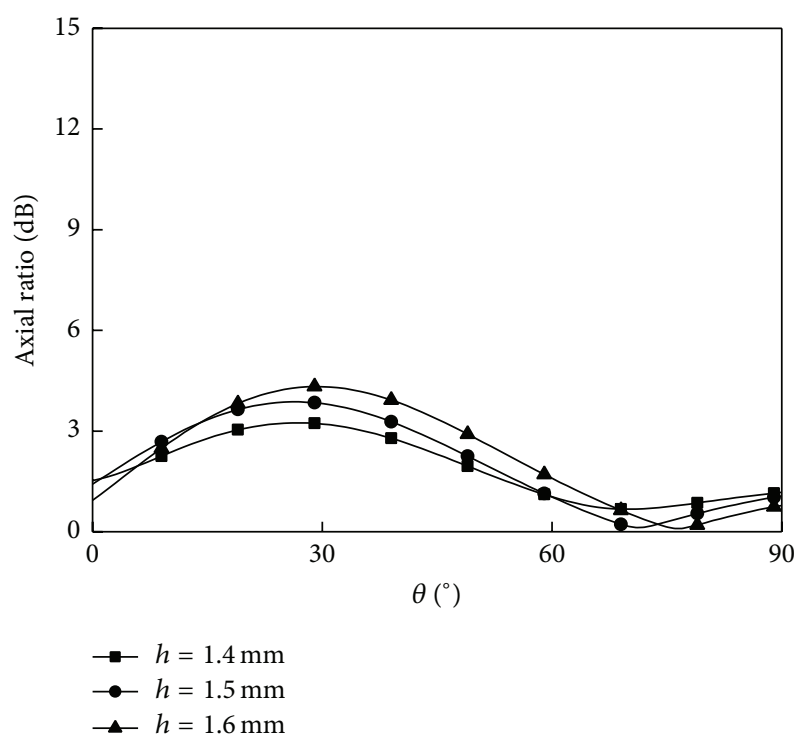

(b) $\mathrm{AR}$

FIGURE 19: The RHCP gain and AR in $x o z$-plane at $5.7 \mathrm{GHz}$ with different $h$.

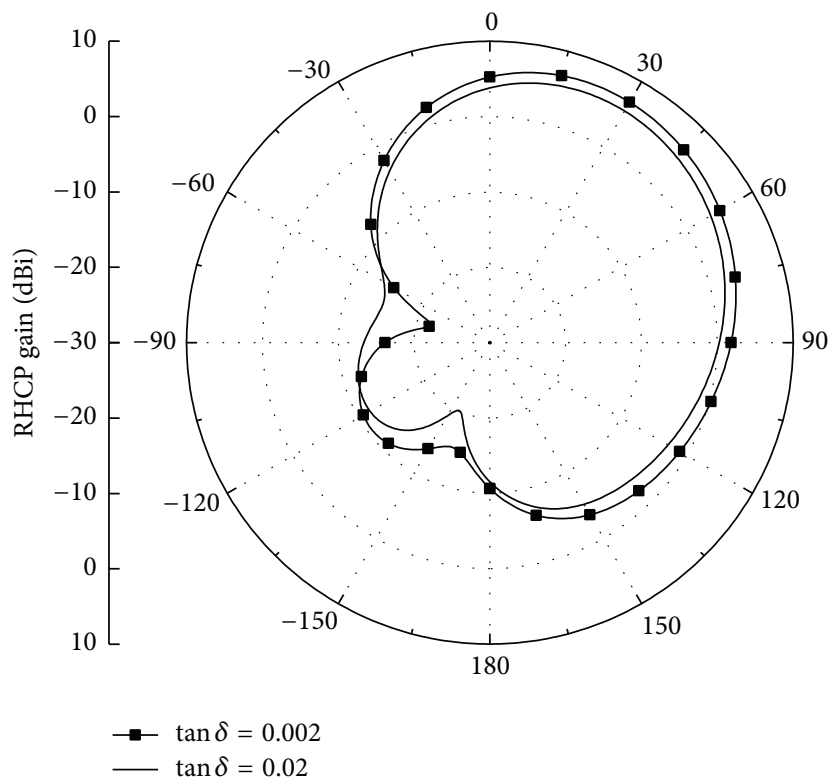

(a) xoz-plane

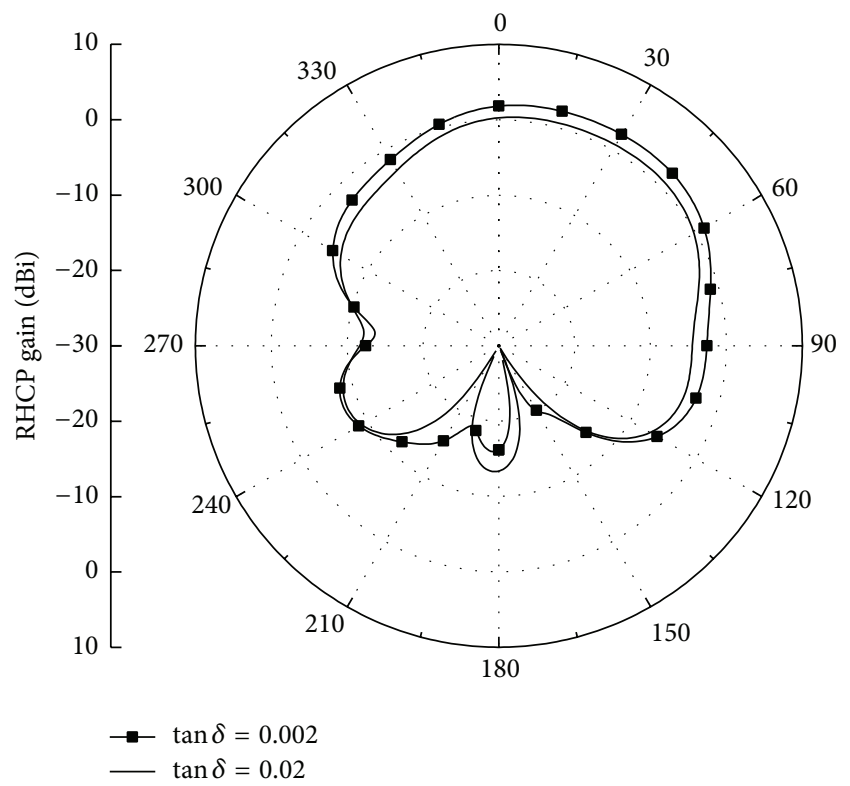

(b) xoy-plane

FIgUre 20: The RHCP gain at $5.7 \mathrm{GHz}$ with different $\tan \delta$.

is $H$-plane coupling and it is lightly affected by $g$, so the resonant frequencies are almost unchanged.

From Figures 9 and 10, the backward radiation significantly increases but the forward radiation slightly varied when $g$ is increased. The value of AR decreases in the front radiation range while the beamwidth becomes narrower when $g$ is increased, and the degree of this change becomes stable when $g$ is large enough.
3.3. The Second-Stage Director Patch Gap $\left(S_{2}\right)$. Figure 11 shows the impedance of the two ports with different $S_{2}$. Because the coupling of two-stage director patches is reduced as $S_{2}$ increased, we can see that the parasitic resonances become weaker and the impedance is decreased. Moreover, the weaker coupling further affects the impedance at the resonant frequency corresponding to the driven patch. From Figures 12 and 13, we know that when $S_{2}$ increase, the 




(a)

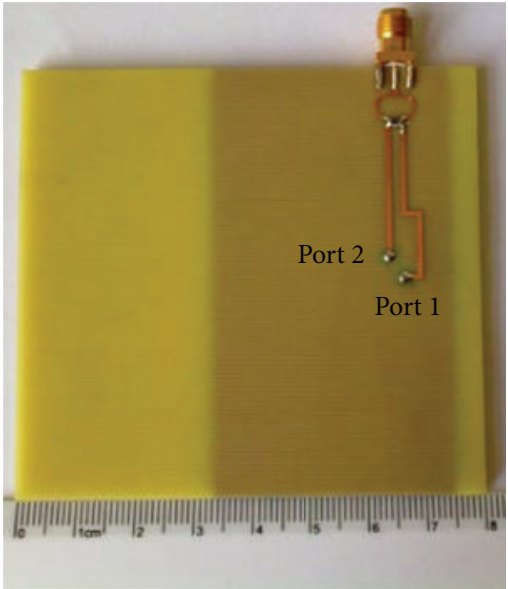

(b)

FIGURE 21: Fabricated Microstrip Yagi array antenna.

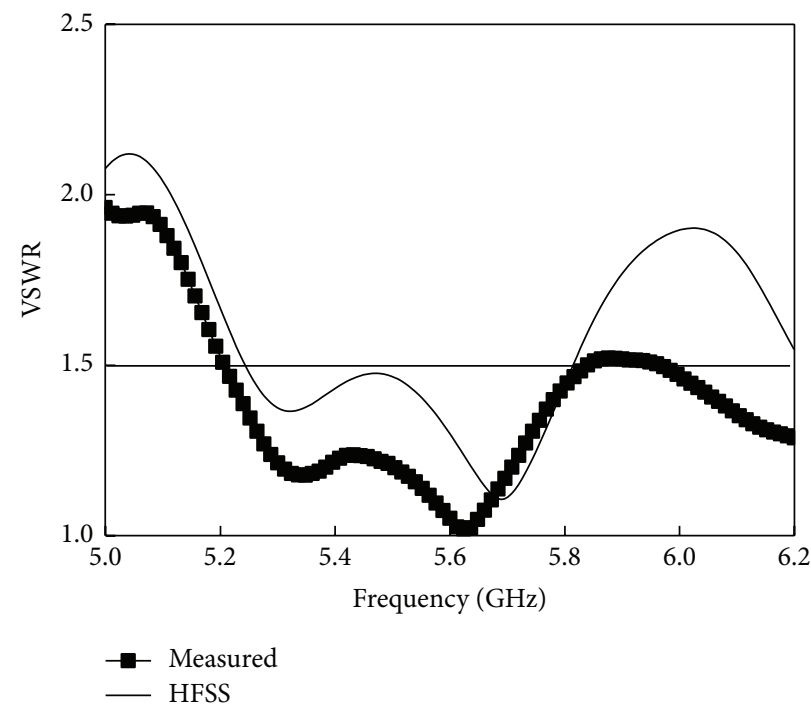

FIGURE 22: Measured and simulated VSWR of the fabricated antenna.

TABLE 3: Measured and simulated VSWR and AR frequency range and bandwidths.

\begin{tabular}{lcccc}
\hline & $f_{L}(\mathrm{GHz})$ & $f_{H}(\mathrm{GHz})$ & $f_{c}(\mathrm{GHz})$ & $B_{w}$ \\
\hline VSWR $\leq 1.5$ & & & & \\
$\quad$ Measured & 5.21 & 5.83 & 5.52 & $11.30 \%$ \\
HFSS & 5.25 & 5.82 & 5.53 & $10.30 \%$ \\
$\quad \Delta$ & 0.04 & 0.02 & 0.01 & $1.00 \%$ \\
AR $\leq 3 \mathrm{~dB}$ & & & & \\
$\quad$ Measured & 5.25 & 5.90 & 5.58 & $11.70 \%$ \\
HFSS & 5.31 & 6.05 & 5.68 & $13.00 \%$ \\
$\Delta$ & 0.06 & 0.15 & 0.11 & $1.30 \%$ \\
\hline
\end{tabular}

beamwidth of the gain and AR in horizontal plane becomes narrower and the forward and backward gain are decreased and increased, respectively. Moreover, AR increases in horizontal plane in the front radiation range but better $\mathrm{CP}$ characteristics appeared in xoz-plane.

3.4. The Substrate $\left(\varepsilon_{r}, \tan \delta, h\right)$. Figures 14 and 15 show the impedance of the two ports with different dielectric constant $\varepsilon_{r}$ and thickness $h$ of the substrate. We can see that the operating frequency moves to lower band when $\varepsilon_{r}$ or $h$ enlarged. This phenomenon is the same as the other microstrip antenna structures, because the electrical size of the antenna is increased when a larger value of the dielectric constant or thickness of the substrate is chosen and the operating frequency of the antenna is reduced. Moreover, the gain and axial ratio of the antenna are sure to vary with the change of working frequency which can be seen obviously in Figures 16-19.

From Figure 20, we can see that the gain is closely related to the loss of the substrate. The bigger loss will produce the lower gain. 


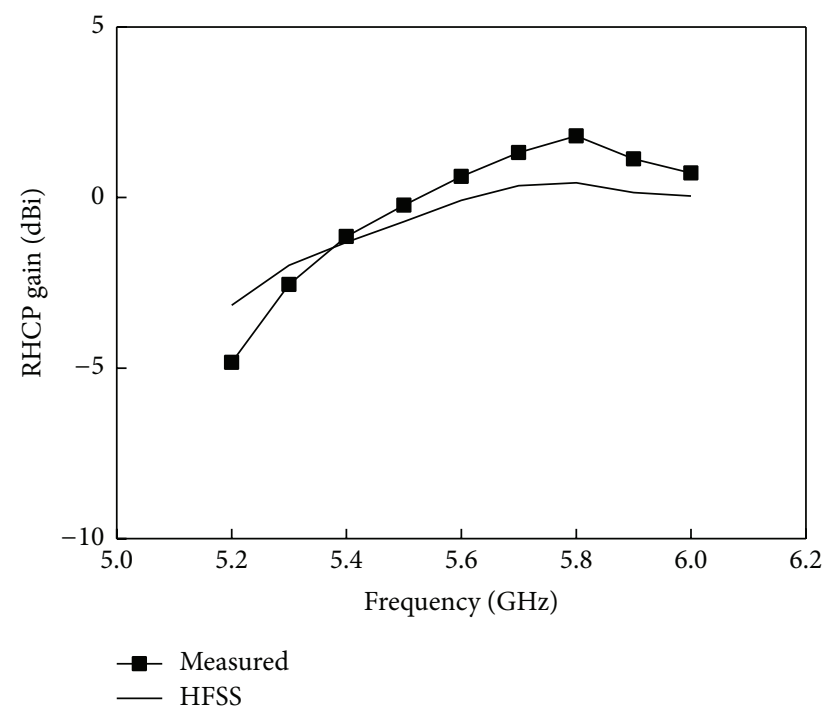

(a) RHCP gain

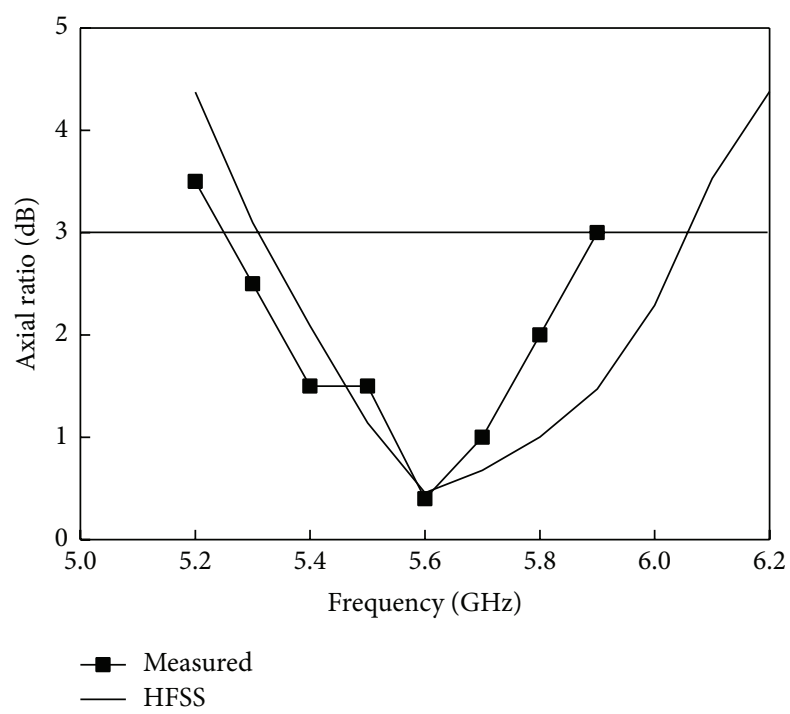

(b) $\mathrm{AR}$

FIGURE 23: Measured and simulated RHCP gain and axial ratio of the fabricated antenna.

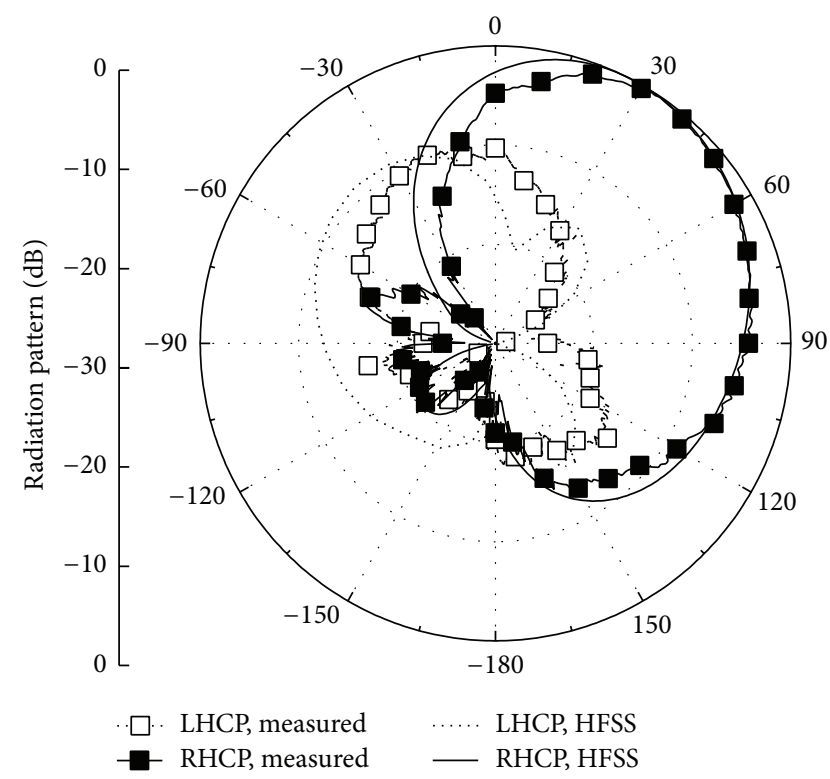

(a) xoz-plane

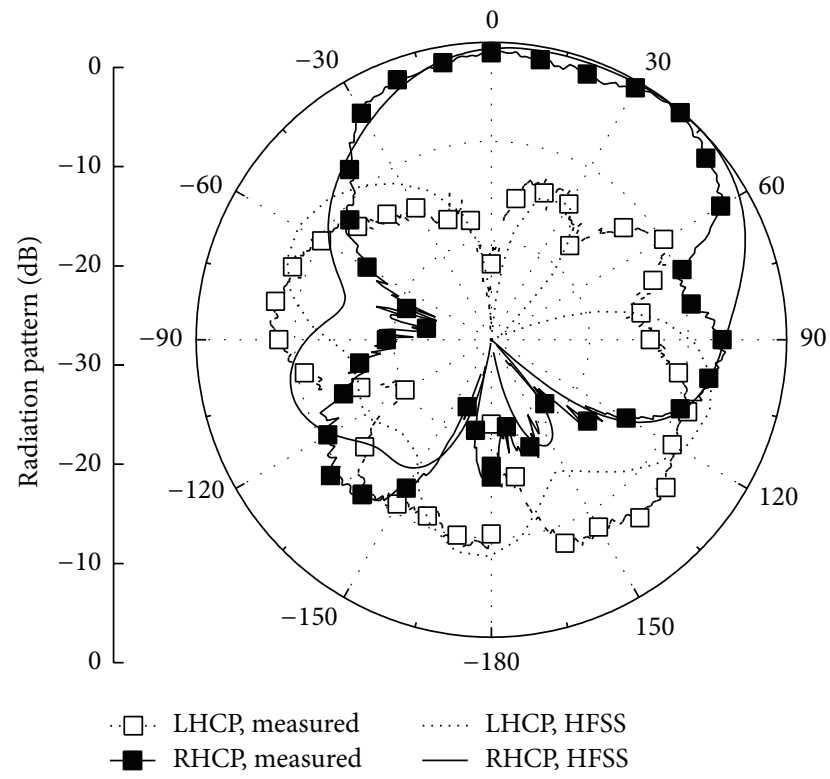

(b) xoy-plane

FIGURE 24: Measured and simulated radiation patterns at $5.6 \mathrm{GHz}$.

\section{Measured Results and Discussions}

In order to verify the analyses mentioned before, an antenna with RHCP radiation is fabricated and tested. The fabricated antenna is shown in Figure 21. The substrate we used is FR4 with the permittivity 4.6 and the loss tangent 0.02 . The thickness is $1.6 \mathrm{~mm}$. According to the results discussed before, a new set of dimensions of the MSYA are shown in Table 2 and the center frequency of it is reduced to $5.6 \mathrm{GHz}$. The two ports have the same amplitude and $100^{\circ}$ phase difference in order to get optimized CP quality. A microstrip Wilkinson power divider $[11,12]$ is used as its feed network. The power from the input port is distributed to port 1 and port 2 averagely and the different lengths of the two legs ensure the phase difference of the two ports. In order to reduce the loss, usually, we make the legs of the Wilkinson divider as short as possible although this loss can reduce the reflection coefficient on the input port. The thickness of the feeding network substrate is $0.6 \mathrm{~mm}$ with the same substrate as the antenna. A $0.16 \mathrm{~mm}$ organic adhesive is used to fix the divider and MSYA together and the equivalent dielectric constant of the organic adhesive is about 3.95.

Figure 22 shows the results of VSWR of the input port. The bandwidth of VSWR $\leq 1.5$ is $11.4 \%(5.21 \mathrm{GHz} 5.84 \mathrm{GHz})$ 


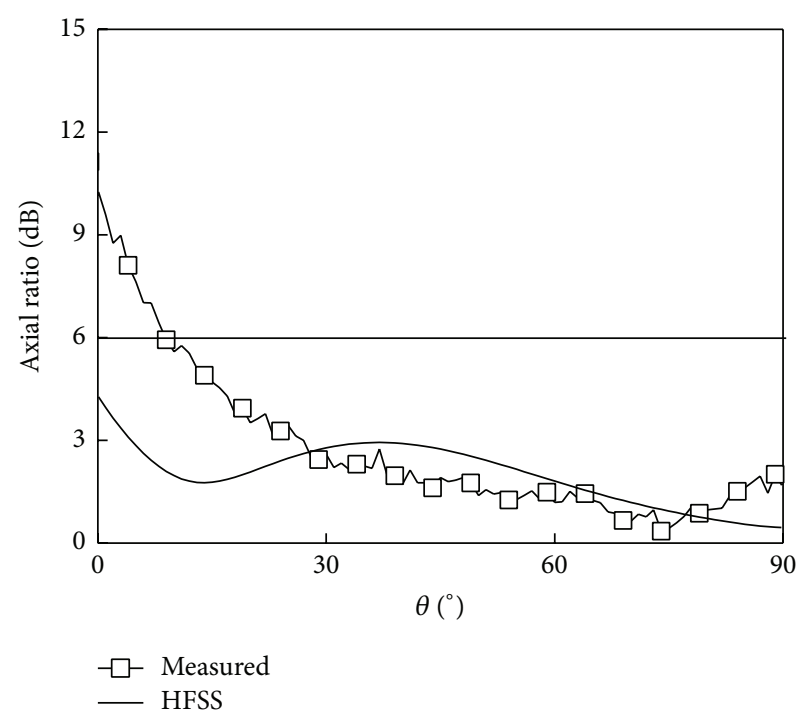

(a) xoz-plane

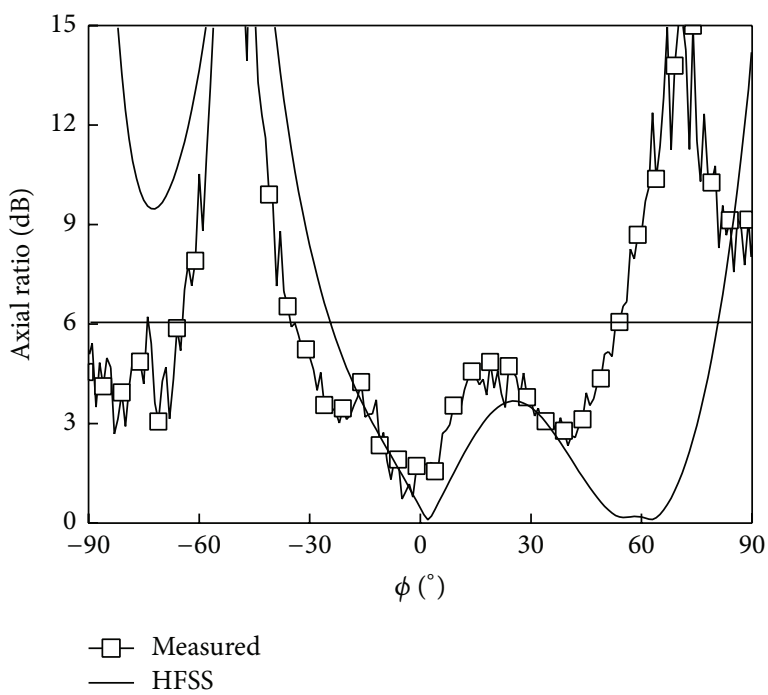

(b) xoy-plane

FIgURE 25: Measured and simulated axial ratio spatial distribution at 5.6 GHz.

TABLE 4: Comparison of the antennas performances.

\begin{tabular}{|c|c|c|c|c|c|c|c|c|c|}
\hline \multirow{2}{*}{ Ant. } & \multirow{2}{*}{$f_{c}(\mathrm{GHz})$} & \multirow{2}{*}{ CP or LP } & \multicolumn{2}{|c|}{ Bandwidth } & \multirow{2}{*}{$\alpha\left(^{\circ}\right)$} & \multirow{2}{*}{$R_{(F / B)}(\mathrm{dB})$} & \multirow{2}{*}{$\Delta G(\mathrm{~dB})$} & \multicolumn{2}{|c|}{$\mathrm{HPBW}\left({ }^{\circ}\right)$} \\
\hline & & & VSWR $\leq 1.5$ & $\mathrm{AR} \leq-3 \mathrm{~dB}$ & & & & $x o z$-plane & xoy-plane \\
\hline Our design & 5.6 & $\mathrm{CP}$ & $11.3 \%$ & $11.7 \%$ & 35 & 19 & 4.3 & 60 & 87 \\
\hline Reference [7] & 1.55 & $\mathrm{CP}$ & - & - & 40 & 4 & 13.5 & 60 & - \\
\hline Reference [10] & 5.2 & LP & $10 \%$ & $x$ & 40 & 15 & 10 & 38 & 75 \\
\hline
\end{tabular}

with the center frequency $5.52 \mathrm{GHz}$ for measured results, which is about $1 \%$ wider, and a slighter frequency shift than the simulated results (Table 3 ). This may be caused by uncertainty of the dielectric materials used in the fabrication and SMA connector effect.

Figure 23 shows the results of the RHCP gain and AR at the front radiation point. Firstly, we can see that the gain is smaller than the values shown in Figure 4. This is because the loss tangent in here is 0.02 and it is ten times less than 0.002. From Figure 20, we know that the lower gain is produced by the bigger loss. We also find that the difference between the measured and simulated values of gain is about $1 \mathrm{~dB}$, and the difference of $3 \mathrm{~dB}$ AR bandwidth is about $1.3 \%$ which is narrower than the simulated results with a slight frequency shift. The test $3 \mathrm{~dB}$ AR bandwidth is about $11.7 \%(5.25 \mathrm{GHz} \sim 5.90 \mathrm{GHz})$ with the center frequency $5.58 \mathrm{GHz}$, and the bandwidth of $3 \mathrm{~dB}$ AR and $\mathrm{VSWR} \leq 1.5$ is $11 \%(5.25 \mathrm{GHz} \sim 5.83 \mathrm{GHz})$.

Figures 24 and 25 show the radiation patterns and AR spatial distribution at $5.6 \mathrm{GHz}$. We found that the steering angle $\alpha$ is $35^{\circ}$ and the difference between $G_{0}$ and $G_{m}$ marked as $\Delta G$ is only $4.3 \mathrm{~dB} . R_{(F / B)}$ is about $19 \mathrm{~dB}$; the HPBW in $x o y$ plane and $x o z$-plane is $87^{\circ}$ and $60^{\circ}$, respectively. Moreover, it has good $\mathrm{CP}$ characteristics that $\mathrm{AR} \leq 6 \mathrm{~dB}$ in the range of $9^{\circ} \leq \theta \leq 90^{\circ}$ in vertical plane and $-35^{\circ} \leq \varphi \leq 53^{\circ}$ in horizontal plane.

We can also find that there are certain angle shifts in spatial range between the measured and simulated results but the simulations have wider beamwidth. These may be caused by the influence of the feeding coaxial line and the test operations.

In order to further evaluate the performance of the antenna, a comparison between our proposed antenna and previously published antennas is shown in Table 4 . We can see that our antenna has the advantages of high $R_{(F / B)}$, small $\Delta G$, and wide radiation beamwidth, which can ensure the communication quality at very low elevation.

\section{Conclusion}

This paper shows a novel CP MSYA with good end-fire characteristics. The measured results agree well with the corresponding simulation results. The overlapped bandwidth of $\mathrm{AR} \leq 3 \mathrm{~dB}$ and VSWR $\leq 1.5$ is about $11 \%$. The front-toback ratio $R_{(F / B)}$ and steering angle $\alpha$ can reach $19 \mathrm{~dB}$ and $35^{\circ}$. Moreover, $\Delta G$ is less than $4.3 \mathrm{~dB}$. The HPBW in $x o y$-plane and $x o z$-plane is $87^{\circ}$ and $60^{\circ}$, respectively. These advantages of the proposed antenna can ensure the communication quality at very low elevation.

\section{Conflict of Interests}

The authors declare that there is no conflict of interests regarding the publication of this paper. 


\section{References}

[1] C. A. Balanis, Antenna Theory Analysis and Design, John Wiley \& Sons, New York, NY, USA, 3rd edition, 2005.

[2] S. K. Padhi and M. E. Bialkowski, "An X-band aperture-coupled microstrip Yagi array antenna for wireless communications," Microwave and Optical Technology Letters, vol. 18, no. 5, pp. 331335, 1998.

[3] S. K. Padhi and M. E. Bialkowski, "Parametric study of a microstrip Yagi antenna," in Proceedings of the Asia-Pacific Microwave Conference, pp. 715-718, IEEE, Sydney, Australia, December 2000.

[4] J. Huang, "Planar microstrip Yagi array antenna," in Proceedings of the IEEE Antennas and Propagation Society International Symposium, vol. 2, pp. 894-897, San Jose, Calif, USA, June 1989.

[5] J. Huang, "Planar microstripYagiantenna array," United States Patent, June 15, 1993.

[6] A. Densmore and J. Huang, "Microstrip Yagi antenna for mobile satellite service," in Proceedings of the Antennas and Propagation Society International Symposium. Digest (AP-S '91), vol. 2, pp. 616-619, IEEE, Ontario, Canada, June 1991.

[7] J. Huang and A. C. Densmore, "Microstrip Yagi array antenna for mobile satellite vehicle application," IEEE Transactions on Antennas and Propagation, vol. 39, no. 7, pp. 1024-1030, 1991.

[8] S. K. Padhi and M. E. Bialkowski, "Investigation of an aperture coupled microstrip Yagi antenna using PBG structure," in Proceedings of the IEEE Antennas and Propagation Society International Symposium, pp. 752-755, San Antonio, Tex, USA, June 2002.

[9] X.-S. Yang, B.-Z. Wang, W. Wu, and S. Xiao, "Yagi patch antenna with dual-band and pattern reconfigurable characteristics," IEEE Antennas and Wireless Propagation Letters, vol. 6, pp. 168171, 2007.

[10] G. R. DeJean and M. M. Tentzeris, "A new high-gain microstrip Yagi array antenna with a high front-to-back (F/B) ratio for WLAN and millimeter-wave applications," IEEE Transactions on Antennas and Propagation, vol. 55, no. 2, pp. 298-304, 2007.

[11] D. M. Pozar, Microwave Engineering, John Wiley \& Sons, New York, NY, USA, 4th edition, 2012.

[12] E. J. Wilkinson, "An N-way hybrid power divider," IEEE Transactions on Microwave Theory and Techniques, vol. 8, no. 1, pp. 116-118, 1960. 


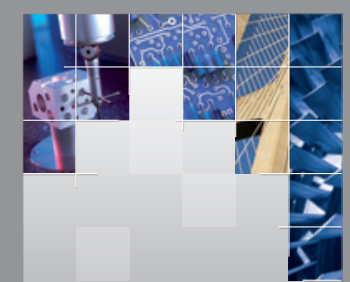

\section{Enfincering}
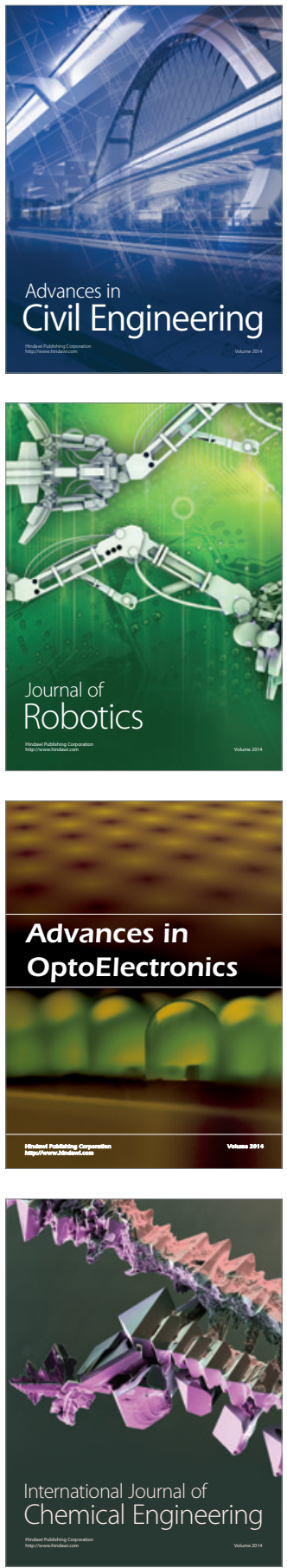

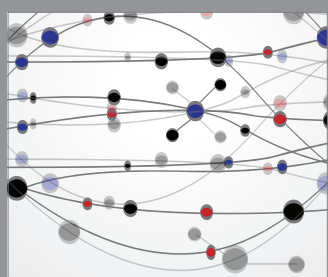

The Scientific World Journal

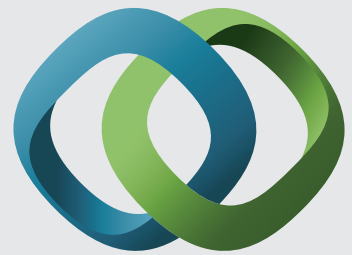

\section{Hindawi}

Submit your manuscripts at

http://www.hindawi.com

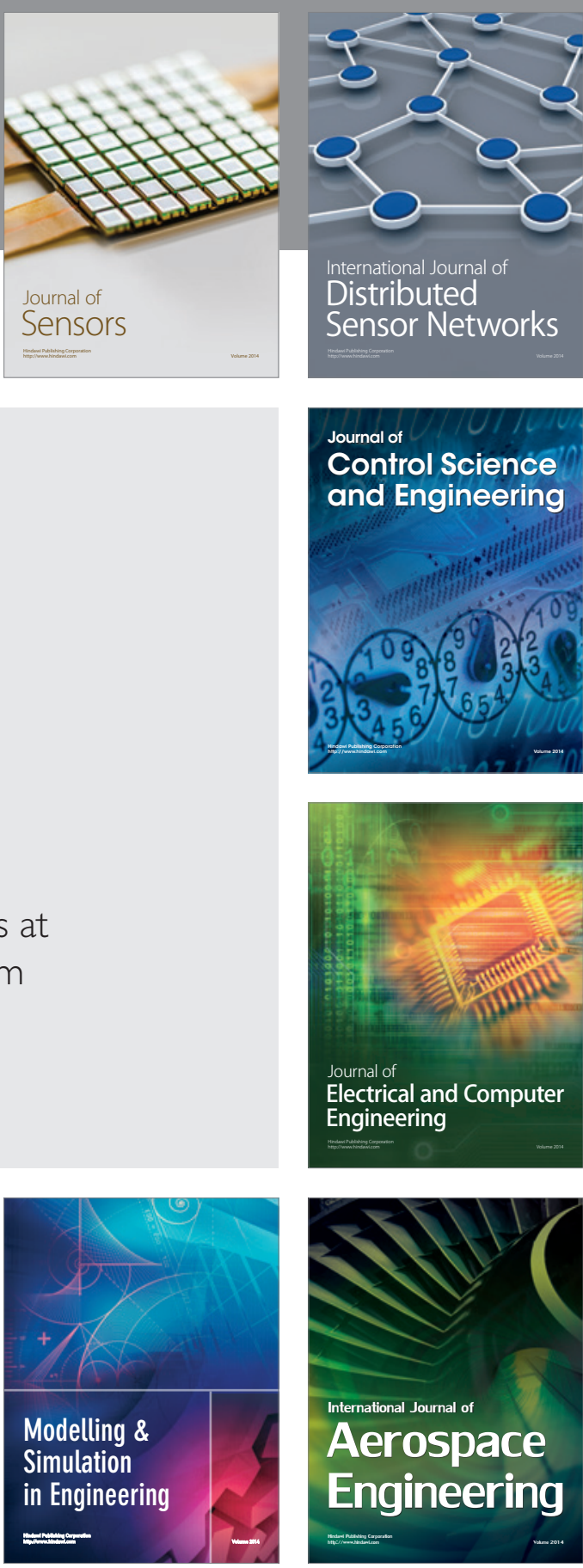

International Journal of

Distributed

Sensor Networks

Journal of

Control Science

and Engineering
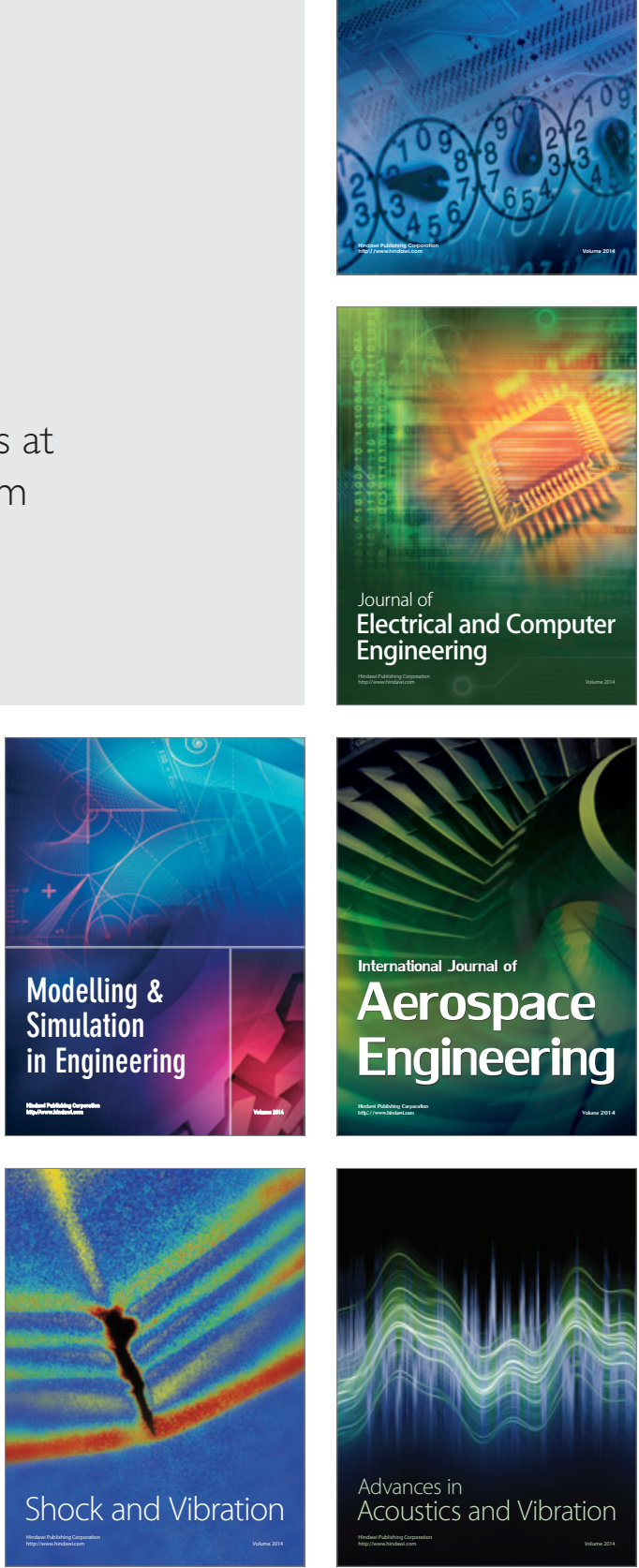